\title{
Preparation and Binding Evaluation of Histamine-Imprinted Microspheres via Conventional Thermal and RAFT-Mediated Free- Radical Polymerization
}

\author{
Edwin F. Romano, Jr., ${ }^{\dagger \dagger}$ Regina C. So, ${ }^{* \dagger}{ }^{\dagger}$ Scott W. Donne, ${ }^{\S}$ and Clovia I. Holdsworth ${ }^{*}$, \\ ${ }^{\dagger}$ Department of Chemistry, Ateneo de Manila University, Schmitt Hall, Loyola Heights, Quezon City 1108, Philippines \\ ${ }^{\ddagger}$ Department of Chemistry, College of Arts and Sciences, Negros Oriental State University, Kagawasan Avenue, Dumaguete City \\ 6200, Philippines \\ ${ }^{\S}$ School of Environmental and Life Sciences, Chemistry Building-C218, University of Newcastle, University Drive, Callaghan, NSW \\ 2308, Australia
}

\section{Supporting Information}

ABSTRACT: Elevated histamine (HTM) levels are closely linked to food poisoning as well as to pathophysiological allergic diseases. In this study, HTM-imprinted, solutionprocessable microspheres were prepared via high-dilution conventional thermal polymerization (CTP) and controlled radical polymerization (CRP) using ethylene glycol dimethacrylate ( 80 or 90 wt \%) and methacrylic acid at $60{ }^{\circ} \mathrm{C}$ in acetonitrile and evaluated as recognition materials for sensing applications. The polymers were selective to HTM in binding studies, cross-rebinding, and competitive binding assays against the HTM analogues histidine, imidazole, and tryptamine. The selective binding capacity was significantly higher with CTP-80 (on the basis of mass: $21.0 \mu \mathrm{mol} / \mathrm{g}$ and surface area: $8.08 \times$

$\left.10^{-2} \mu \mathrm{mol} / \mathrm{m}^{2}\right)$ than that with both CTP-90 $\left(8.47 \mu \mathrm{mol} / \mathrm{g}, 4.49 \times 10^{-2} \mu \mathrm{mol} / \mathrm{m}^{2}\right)$ and CRP-80 $\left(9.00 \mu \mathrm{mol} / \mathrm{g}, 1.19 \times 10^{-2}\right.$ $\left.\mu \mathrm{mol} / \mathrm{m}^{2}\right)$.

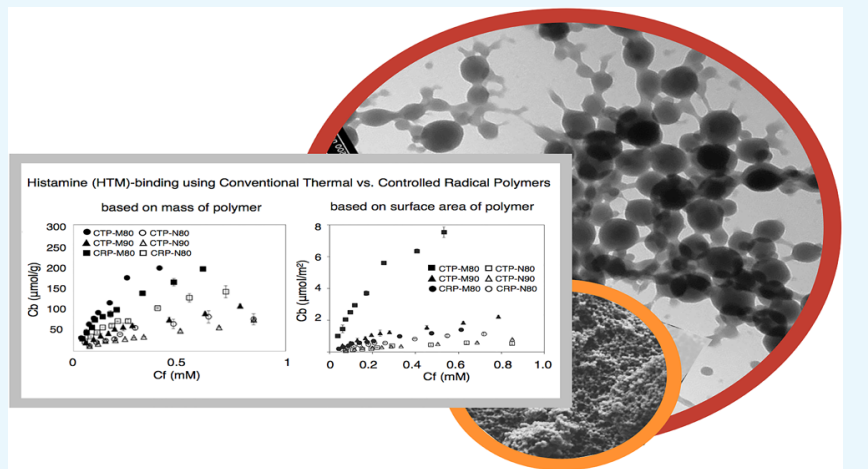

\section{INTRODUCTION}

Molecularly imprinted polymers (MIPs) are synthetic materials with recognition properties that have been used in separation, catalysis, chemical sensing, and drug-discovery applications. ${ }^{1,2}$ The first generation of MIPs was prepared using traditional polymerization processes, in which polymer chain propagation and termination were hard to control. This often resulted in irregularly shaped, monolithic polymers that required grinding and sieving before use. ${ }^{3}$ In addition, these polymers were insoluble in most solvents and required exhaustive extraction for removal of the template. The presence of heterogeneous pockets within the polymer network structures also sometimes compromised the binding of the material with the template, resulting in low-affinity or nonselective binding. Over the years, the development of traditional radical precipitation polymerization (TRPP) allowed the preparation of MIPs in nano/ submicrosphere formats. This process involved reaction under highly dilute conditions, where soluble branched oligomers were continuously captured from the solution, leading to the growth of the particles. Progressive growth occurred until the particles were no longer soluble in the reaction medium. Unlike that in emulsion or surfactant polymerization, no extra stabilizer was needed. ${ }^{4,5}$
Recently, controlled radical polymerization (CRP) techniques, namely, atom transfer radical polymerization, ${ }^{6,7}$ reversible addition fragmentation transfer (RAFT), ${ }^{8}$ nitroxide-mediated ${ }^{9}$ and photochemical-iniferter-induced ${ }^{10}$ polymerization, have been found to allow the generation of reactive chains that can undergo reversible propagation/termination cycles. The process involves a reversible chain transfer agent (CTA; typically a dithioester for RAFT), where there is a dynamic equilibrium between the active propagating radical species and the inactive thiocarbonylthio-terminated species. When a RAFT agent is introduced during precipitation polymerization, the RAFT mechanism can be imparted to the reaction. The controlled nature of RAFT polymerization is attractive for the preparation of MIPs, providing polymers with increased structural homogeneity and improved properties in comparison with those of the MIPs prepared via TRPP. ${ }^{11-13}$ In addition, functional polymer microspheres with tailor-made recognition sites and functional dithioester surface end groups can be produced. These dithioester groups facilitate further reaction or surface modification by reinitiation via RAFT polymer-

Received: July 23, 2016

Accepted: September 9, 2016

Published: October 6, 2016 
<smiles>NCCc1c[nH]cn1</smiles>

1

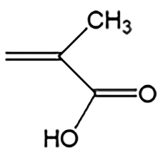

5<smiles>N[C@@H](Cc1c[nH]cn1)C(=O)O</smiles>

2<smiles>C=C(C)C(=O)OCCOC(=O)C(=C)C</smiles>

6<smiles>c1c[nH]cn1</smiles>

3<smiles>NCCc1c[nH]c2ccccc12</smiles>

4

Figure 1. Structures of HTM (1), HTD (2), IDZ (3), TTM (4), MAA (5), EGDMA (6), and MCEBTTC (7).

ization. ${ }^{14,15}$ Recent reports have shown that favorable properties are attributed to the use of RAFT agents in precipitation polymerization. MIPs prepared via CRPs exhibited improved binding, such as faster binding kinetics, ${ }^{15}$ higher binding capacities, ${ }^{12,14,16-19}$ and larger binding association constants, $K_{\mathrm{a}}$ and $N_{\max }$ when calculated using the conventional method of binding per mass of the particle. ${ }^{12}$

Submicron-sized polymeric particles (i.e., microgels, nanogels, microspheres, or simple nanoparticles) are popular formats of choice in molecular imprinting. MIP nanoparticles exhibited better binding kinetics due to the presence of more accessible imprinted sites. ${ }^{20-22}$ Further, they can be dispersed in solution, which allows easy characterization using standard procedures for highly soluble macromolecules (processable). MIP nanoparticles have been prepared by a number of methods, including solution polymerization, precipitation polymerization, and mini- and micro-emulsion polymerization. Solution radical polymerization was successfully demonstrated by Wulff's group in the preparation of solution-processable sugar-imprinted microgels, ${ }^{20}$ with a crosslinking degree of 5090 wt $\%$. The same technique was also used in the preparation of soluble imprinted nano/microgels with catalytic properties. $^{21,22}$ Haupt's group ${ }^{23}$ utilized high-dilution surfactant-free precipitation polymerization to prepare water-soluble microgels, which act as enzyme inhibitors. Vaihinger et al. ${ }^{24}$ produced enantioselective imprinted nanospheres via miniemulsion polymerization.

The work presented here involves the preparation and binding evaluation of solution-processable histamine (HTM)imprinted microspheres (MIM) by high-dilution radical polymerization using an azo initiator $\left(2,2^{\prime}\right.$-azobis (2-methylpropionitrile) (AIBN)) via conventional thermal polymerization (CTP) and CRP using methyl-2-(butylthiocarbonothioylthio)propanoate (MCEBTTC) as the CTA. To date, this CTA has not been applied to any RAFT-mediated precipitation polymerization for MIP preparation. In addition, since this study, only Trikka et al. have reported on the use of polymer precipitates as a HTM-recognition material. ${ }^{25}$ Hence, the motivations of this study were as follows: to increase our understanding on the use of CTA in RAFT polymerization, to prepare processable MIPs that can be used as recognition elements for optical-based HTM sensing, and to analyze the binding data expressed with respect to mass versus surface area. Our investigation focused on the influence of the initiation/ polymerization method on the binding performance of these HTM-imprinted microspheres.

HTM (1), the template of choice for this study, is one of the biogenic amines associated with food spoilage s6,27 $^{2}$ and pathophysiological conditions related to allergy. ${ }^{28-30} \mathrm{HTM}$ is found naturally in foods, such as vegetables, fruits, fish, and cheese, in small quantities. Elevated levels of HTM occur as foods spoil, which when ingested can result in food poisoning. Hence, HTM levels are used to monitor and assess the safety and quality of food products to ensure that the concentration does not go beyond its safe threshold (i.e., 50 ppm, $5 \mathrm{mg} / 100$ g). ${ }^{31}$ HTM is also found in human tissues at relatively low concentrations $(0.1-20 \mu \mathrm{g} / \mathrm{g})$. It is stored primarily in mast cells in tissues and basophils in blood, where it is tightly bound with heparin in membrane-bound granules. Upon exposure of cells to an antigen or a wide range of drugs, HTM can be released. ${ }^{30}$ Thus, there is a need to develop assays to measure HTM levels in food, urine, and tissues.

\section{EXPERIMENTAL SECTION}

Materials and Reagents. HTM (1), L-histidine (HTD, 2), imidazole (IDZ, 3), and tryptamine (TTM, 4) were purchased from Sigma-Aldrich and used as received. Methacrylic acid (MAA, 5) and ethylene glycol dimethacrylate (EGDMA, 6) were purchased from Sigma-Aldrich and purified by passing through basic alumina $\left(\mathrm{Al}_{2} \mathrm{O}_{3}\right)$ columns. AIBN was obtained from Sigma-Aldrich and recrystallized in ethanol twice before use. Carbon disulfide and 1-butanethiol (both from SigmaAldrich) were used as received. MCEBTTC (7) was synthesized according to the procedure outlined below. Highperformance liquid chromatography (HPLC)-grade solvents, such as dimethyl sulfoxide (DMSO) (Sigma-Aldrich), acetonitrile (MeCN) (Honeywell Burdick \& Jackson), and methanol (Fisher Scientific), were used without further purification. $\mathrm{Na}_{2} \mathrm{HPO}_{4}$ (BDH Chemicals), $\mathrm{NaH}_{2} \mathrm{PO}_{4} \cdot 2 \mathrm{H}_{2} \mathrm{O}$ (AJAX Chemicals), $\mathrm{KH}_{2} \mathrm{PO}_{4}$ (Sigma-Aldrich), and $\mathrm{H}_{3} \mathrm{PO}_{4}$ (85\%) (SigmaAldrich) were used as received (Figure 1).

Synthesis of RAFT Agent MCEBTTC, 7. MCEBTTC was synthesized according to the procedure in the literature. ${ }^{32}$ Briefly, carbon disulfide $(6.18 \mathrm{~mL}, 0.103 \mathrm{~mol})$ dissolved in dichloromethane (DCM) $(50 \mathrm{~mL})$ was added to a stirred solution of 1-butanethiol $(10 \mathrm{~mL}, 0.093 \mathrm{~mol})$ and triethylamine $(14.3 \mathrm{~mL}, 0.103 \mathrm{~mol})$ in DCM $(100 \mathrm{~mL})$ at $0{ }^{\circ} \mathrm{C}$ under $\mathrm{N}_{2}$ over $30 \mathrm{~min}$. This reaction mixture was stirred for $1 \mathrm{~h}$, followed by the addition of 1-methylbromopropionate $(11.5 \mathrm{~mL}, 0.103$ 
$\mathrm{mol})$ in DCM $(50 \mathrm{~mL})$, and this mixture was stirred for $2 \mathrm{~h}$. After the reaction, DCM was removed and the residue was dissolved in diethyl ether. This solution was then washed with cold $10 \% \mathrm{HCl}$ solution $(3 \times 50 \mathrm{~mL})$ and MilliQ water $(3 \times 50$ $\mathrm{mL}$ ) and then dried over anhydrous $\mathrm{MgSO}_{4}$. The ether was removed under vacuum and the residual yellow oil was purified by column chromatography (9:1 petroleum ether/ethyl acetate on silica). Subsequently, a yellow RAFT agent was obtained. ${ }^{1} \mathrm{H}$ $\operatorname{NMR}\left(\mathrm{CDCl}_{3}\right): \delta=0.92\left(\mathrm{t}, J=7.5 \mathrm{~Hz}, 3 \mathrm{H}, \mathrm{CH}_{3}\right), 1.43$ (mult, $J$ $\left.=7.5 \mathrm{~Hz}, 2 \mathrm{H}, \mathrm{CH}_{2}\right), 1.62\left(\mathrm{~d}, J=7.5 \mathrm{~Hz}, 3 \mathrm{H}, \mathrm{CH}_{3}\right), 1.65$ (quin, $\left.J=7.5 \mathrm{~Hz}, 2 \mathrm{H}, \mathrm{CH}_{2}\right), 3.36\left(\mathrm{t}, J=7.5 \mathrm{~Hz}, 2 \mathrm{H}, \mathrm{CH}_{2}\right), 3.73(\mathrm{~s}$, $\left.3 \mathrm{H}, \mathrm{CH}_{3}\right), 4.84(\mathrm{q}, J=7.5 \mathrm{~Hz}, 1 \mathrm{H}, \mathrm{CH}) ;{ }^{13} \mathrm{C} \mathrm{NMR}\left(\mathrm{CDCl}_{3}\right): \delta$ $=13.55,16.91,22.02,29.89,36.94,47.68,52.82,171.6[\mathrm{CH}-$ $\mathrm{C}(=\mathrm{O})-\mathrm{O}], 221.9[\mathrm{~S}-\mathrm{C}(=\mathrm{S})-\mathrm{S}]$.

Synthesis of Microspheres: Determination of Critical Monomer Concentration for Precipitation (cmcp) and Solution Processability. Microspheres were prepared using an MAA/EGDMA (functional monomer/crosslinker) ratio of $30: 70,20: 80$, or 10:90 wt \%. The monomer concentration was varied from 1 to $10 \mathrm{wt} \%$ of the total solution and diluted with an appropriate solvent. The initiator, AIBN (3 wt \% with respect to the monomer concentration), was added to the reaction mixture and subsequently purged with $\mathrm{N}_{2}$ for $5 \mathrm{~min}$. Thermal polymerization was carried out with stirring at 300 $\mathrm{rpm}$ at $60^{\circ} \mathrm{C}$ for $24 \mathrm{~h}$. After polymerization, the microspheres were isolated by solvent evaporation, for those prepared in $\mathrm{MeCN}$, or dialysis in water, for those prepared in DMSO. Once dried, the microspheres were washed with diethyl ether $(20$ $\mathrm{mL}$ ) at least three times to remove the unreacted monomers. Using the above procedure, different formulations for microsphere preparation were derived (Table 1).

Table 1. Yields and Processabilities of Microspheres Prepared in Various Monomer Feed Concentrations by High-Dilution Polymerization in $\mathrm{MeCN}$

$\begin{array}{ccccc}\text { sample } & \begin{array}{c}\text { feed conc. } \\ \text { (wt \%) }\end{array} & \begin{array}{c}\text { rxn time } \\ (\mathrm{h})\end{array} & \begin{array}{c}\text { yield }^{a} \\ (\%)\end{array} & \begin{array}{c}\text { processability }^{b} \\ \text { N90 }\end{array} \\ & 4 & 3 & \sim 40 & \begin{array}{c}\text { processable in all solvents } \\ \text { tested }\end{array} \\ & & 6 & \sim 80 & \text { DMSO, DMF, THF, MeCN } \\ & & 24 & \sim 80 & \\ & 5 & 24 & >90 & \\ \text { N80 } & 4 & 24 & >80 & \text { Dot processable in all solvents } \\ & 5 & 24 & >90 & \text { DMSO, DMF, THF, MeCN } \\ & 5 & 24 & >80 & \text { DMSO, DMF, THF, MeOH } \\ \text { N70 } & 4 & 24 & >90 & \end{array}$

${ }^{a}$ Ability of the microgels to dissolve or form stable dispersions in a solvent. ${ }^{b}$ Test solvents: $\mathrm{H}_{2} \mathrm{O}, \mathrm{MeOH}, \mathrm{DMSO}$, dimethylformamide (DMF), MeCN, tetrahydrofuran (THF), $\mathrm{CHCl}_{3}, \mathrm{DCM}$, diethyl ether. ${ }^{c}$ Yield was based on the approximate amount of solid residue collected after drying over the initial weight of the monomer feed used during thermal polymerization at $60^{\circ} \mathrm{C}$.

Processability tests on the microspheres were conducted using the following solvents of different polarities: water, methanol $(\mathrm{MeOH}), \mathrm{DMSO}, \mathrm{DMF}, \mathrm{MeCN}, \mathrm{THF}$, chloroform $\left(\mathrm{CHCl}_{3}\right), \mathrm{DCM}$, and diethyl ether. Approximately $1 \mathrm{mg}$ of microsphere was added with incremental amounts of solvent until $5 \mathrm{~mL}$.

Synthesis of HTM-Imprinted Microspheres. MIMs were synthesized in the presence of HTM. In the case of CTP, polymerization was carried out upon the addition of 3 wt $\%$ AIBN to a monomer feed concentration of $\sim 4 \mathrm{wt} \%$, containing EGDMA ( 80 or 90 wt \%) and a 1:4 mole ratio of HTM/MAA (20 or $10 \mathrm{wt} \%)$ in $\mathrm{MeCN}$. The monomers were allowed to react at $60{ }^{\circ} \mathrm{C}$ for $24 \mathrm{~h}$. A non-imprinted, that is, no template added, equivalent (NIM) was also prepared vis-à-vis each MIM formulation.

CRP MIMs were prepared using the same formulation and polymerization conditions as those above except with the addition of $3 \mathrm{~mol} \mathrm{\%}$ with respect to the total monomer concentration ( $23 \mathrm{mg}$ in $480 \mathrm{mg}$ of feed) of RAFT agent 7 and $20 \mathrm{~mol} \%$ (3 mg) AIBN with respect to the amount of RAFT agent.

The template (HTM) was removed by stirring the polymers in $10 \%$ acetic acid in $\mathrm{MeOH}(\sim 30 \mathrm{~mL})$ for at least $60 \mathrm{~min}$. Subsequently, the microspheres were washed with $\mathrm{MeOH}(5 \times$ $30 \mathrm{~mL})$ with stirring $(\sim 5 \mathrm{~min})$ and subjected to centrifugation for $10 \mathrm{~min}$ at $4000 \mathrm{rpm}$. Finally, the microspheres were washed in diethyl ether prior to drying in a vacuum oven at $40{ }^{\circ} \mathrm{C}$.

Template Rebinding Studies. Sorption of HTM onto the polymer was determined by suspending an appropriate amount of microspheres in a known concentration of HTM aqueous solution for the desired time and measuring the difference in the concentrations of HTM before and after sorption. Typically, a rebinding assay is carried out using $2 \mathrm{mg}$ of microspheres suspended in a $0.10-2.0 \mathrm{mM}$ HTM $(1 \mathrm{~mL})$ solution, buffered using $25 \mathrm{mM} \mathrm{Na} \mathrm{HPO}_{4} / \mathrm{NaH}_{2} \mathrm{PO}_{4}$ at $\mathrm{pH} 7$ (the buffer was prepared by dissolving $239.2 \mathrm{mg}$ of $\mathrm{NaH}_{2} \mathrm{PO}_{4}$. $2 \mathrm{H}_{2} \mathrm{O}$ and $137.3 \mathrm{mg}$ of $\mathrm{Na}_{2} \mathrm{HPO}_{4}$ in $100.0 \mathrm{~mL}$ of reverseosmosis water, 15.33 and $9.67 \mathrm{mM}$, respectively). After centrifugation and filtration of the microspheres, the supernatant was analyzed on a Shimadzu HPLC (LC-20AD) fitted with an EconosphereTM C18 $5 \mu \mathrm{m}$ column (Grace), and the mobile phase was composed of $20 \% \mathrm{MeCN}$ and $80 \%$ buffer solution ( $25 \mathrm{mM} \mathrm{KH}_{2} \mathrm{PO}_{4}$ with $10 \mathrm{mM}$ triethylamine, adjusted to $\mathrm{pH} 3.0$ using $85 \% \mathrm{H}_{3} \mathrm{PO}_{4}$ ). The volume of sample injected was $10 \mu \mathrm{L}$, with a run time of $5.0 \mathrm{~min}$. The flow rate was set to $0.7 \mathrm{~mL} / \mathrm{min}$, using a detection wavelength of $215 \mathrm{~nm}$. The retention time of HTM was around $3.0 \mathrm{~min}$. The calibration curve for HTM was generated using the concentration range of 0.200-5.00 mM. Data were processed using LC software.

Figure 5A,B (or Figure S7A,B in the Supporting Information) was plotted by taking the values obtained from the equilibrium concentrations of bound $(\mathrm{B}), C_{\mathrm{b}}$, and free $(\mathrm{F})$, $C_{f}$, HTM in the heterogeneous solution. The data were expressed in $\mu \mathrm{mol} / \mathrm{g}$, on the basis of the mass of the polymer, or in $\mu \mathrm{mol} / \mathrm{m}^{2}$, with respect to the surface area. The log form (eq 2) was utilized for deriving the two fitting parameters, a (capacity) and $m$ (heterogeneity index), where these two factors together with eqs 3 and 4 were subsequently used for the affinity distribution plots (Figure 5C,D or Figure S7C,D). The number of binding sites, $N$, in Table 3 was obtained using eq $3 . K$ is the inverse of the concentration of the free template $\left(C_{\mathrm{f}} ; F_{\min }\right.$ or $\left.F_{\max }\right)$ in the suspending solution (eq 4$)$. The AD expression can be plotted for any range of binding affinities within the concentration range of the experimental binding isotherm.

$$
\begin{aligned}
& B=a F^{m} \\
& \log B=m \log F+\log A \\
& N=2.303 a m\left(1-m^{2}\right) K^{-m}=N_{\text {term }} K^{-m}
\end{aligned}
$$




$$
K_{\max }=\frac{1}{F_{\min }} \text { and } K_{\min }=\frac{1}{F_{\max }}
$$

Selectivity and Competitive Binding Studies. Selectivity rebinding tests were carried out on $2 \mathrm{mg}$ of microspheres with structural analogues HTD (2), IDZ (3), and TTM (4) using $1 \mathrm{~mL}$ of $1 \mathrm{mM}$ aqueous solution of each analyte, buffered at $\mathrm{pH} \mathrm{7,} \mathrm{similar} \mathrm{to} \mathrm{the} \mathrm{procedure} \mathrm{above} \mathrm{for} \mathrm{the} \mathrm{HTM-binding}$ assay. Competitive binding was performed by suspending $2 \mathrm{mg}$ of microspheres in $1 \mathrm{~mL}$ of aqueous solution (buffered at $\mathrm{pH} 7$ ) containing $1 \mathrm{mM}$ of each of the three competitors and HTM.

Morphology Studies. The morphology of the microspheres was determined using a Sigma Field Emission Scanning Electron Microscope (Zeiss FESEM and Bruker EDS). The samples were prepared by drying the microspheres in vacuum at $40{ }^{\circ} \mathrm{C}$ for $2-3 \mathrm{~h}$; they were then transferred to the surface of the sample holder. Scanning electron microscopy (SEM) analyses were subsequently conducted, with the chamber pressure set at $1.01 \times 10^{-5}$ Torr. The samples were directly analyzed on a carbon background and scanned using a $1.50 \mathrm{kV}$ electron beam with a secondary electron detector. The images were viewed at $15000 \times$ and $33000 \times$ magnifications. The particle size, that is, the diameter, was estimated using Image J software by randomly selecting and averaging the sizes of at least 100 particles.

Particle-Size Determination. Particle sizing was performed at $20{ }^{\circ} \mathrm{C}$ using a dynamic light scattering (DLS) Malvern Zetasizer Nano ZS equipped with a $\mathrm{He}-\mathrm{Ne}$ laser system tuned at $632.8 \mathrm{~nm}$. The runs were carried out with a detection angle of $175^{\circ}$ (backscatter). The measurement setting was adjusted using polyethylene glycol dimethacrylate as the reference material, with a refractive index of 1.51. DMSO was used as a dispersant.

The microspheres $(\sim 0.200 \mathrm{mg})$ were dispersed in $1 \mathrm{~mL}$ of DMSO and sonicated for $20 \mathrm{~min}$. An aliquot of $100 \mu \mathrm{L}$ (dispersed microspheres) was diluted with $1.5 \mathrm{~mL}$ of DMSO. Measurements of the filtered dispersions were taken at 4.65 $\mathrm{mm}$ and an attenuation value between 6 and 10. The hydrodynamic particle size was expressed as peak mean $\left(D_{\mathrm{h}}\right)$; the particle size distribution was indicated as the polydispersity index (PDI) and determined using Cumulants analysis with the Zetasizer v6.12 software.

Surface Area and Porosity. Gas adsorption analysis was carried out using a Micrometrics ASAP 2020 Accelerated Surface Area and Porosity instrument (Norcross, GA). The samples $(100 \mathrm{mg})$ were degassed at $110{ }^{\circ} \mathrm{C}$ under vacuum for at least $12 \mathrm{~h}$, after which adsorption isotherms were obtained using nitrogen as the adsorbate at a temperature of $500{ }^{\circ} \mathrm{C}$, covering a partial pressure $\left(P / P_{0}\right)$ range from $1 \times 10^{-6}$ to 1.0 . The specific surface area and pore size distribution of each sample were determined from the adsorption data using the linearized Brunauer-Emmett-Teller (BET) and Barrett, Joyner, and Halenda (BJH) models, respectively.

\section{RESULTS AND DISCUSSION}

Determination of $\mathrm{cmcp}$ and Processability Tests. The microspheres used for this study were prepared via highdilution conventional radical polymerization, employing MAA as the monomer and EGDMA as the crosslinker. MAA and EGDMA were included in the formulation because the microspheres will subsequently be utilized for the preparation of HTM-imprinted MIMs. MAA with EGDMA as the crosslinker has been shown to be an effective functional monomer for HTM-imprinted polymers in previous studies. $^{25,33}$

Initially, $\mathrm{MeCN}$ and DMSO were chosen as polymerization solvents on the basis of the solubilities of the components of the reaction (MAA and EGDMA) as well as of HTM. Stock EGDMA/MAA monomer feed mixtures containing 90 (N90), 80 (N80), and 70 (N70) wt \% EGDMA were diluted with a fixed amount $(5.0 \mathrm{~mL})$ of solvent (MeCN or DMSO) to obtain various monomer feed concentrations between 1 and 10 wt \%.

In the case of DMSO, reaction mixtures of various monomer feed concentrations (1-10 wt \%) and compositions (N90, $\mathrm{N} 80$, and N70) were polymerized at $60{ }^{\circ} \mathrm{C}$ for $24 \mathrm{~h}$ to determine the critical oligomer degree of polymerization for precipitation (as per IUPAC nomenclature), ${ }^{34}$ herein referred to as the $\mathrm{cmcp}$, that is, the highest monomer concentration that does not result in precipitation or gel formation during polymerization. ${ }^{20}$ The apparent cmcp was observed to decrease with increasing EGDMA content and found to be 2 wt \% for $\mathrm{N} 90$ and 4 wt \% for both N80 and N70, with yields $>80 \%$. After isolation and drying, the processability of the polymers was tested in a number of organic solvents of varying polarities, including water, $\mathrm{MeOH}, \mathrm{DMSO}, \mathrm{DMF}, \mathrm{MeCN}, \mathrm{THF}, \mathrm{CHCl}_{3}$, DCM, and diethyl ether. As the CTP polymers were prepared under dilute precipitation polymerization conditions, particle growth takes place, as low-molecular-weight oligomers are continuously captured, leading to the formation of bigger and more rigid microgels. When these microgels are big enough, their solubilities in the reaction medium can vary from insoluble precipitates to colloidal suspensions. Polymer precipitates are usually difficult to disperse in a given solvent (nonprocessable). However, the polymers prepared in this study can be dispersed in common organic solvents. Hence, we define processability as the ability of a polymer to form stable dispersions in a given solvent. All polymers obtained above the apparent $\mathrm{cmcp}$ (i.e., $\geq 2$ wt $\%$ for $\mathrm{N} 90$ and $\geq 4$ wt $\%$ for N80 and N70) were not processable in the test solvents, even at a high dilution, that is, a $0.15 \% \mathrm{w} / \mathrm{v}$ polymer suspension (27 times lower than the estimated $\mathrm{cmcp}$ ), and even after being subjected to continuous shaking and heating at $60{ }^{\circ} \mathrm{C}$ for $1 \mathrm{~h}$. This observation suggests that the polymers obtained above the apparent cmcp may no longer be microspheres/microgels. Stöver and co-workers ${ }^{35,36}$ have also observed microgel to macrogel transition at high volume fractions of good solvents (i.e., $>85 \mathrm{vol} \% \mathrm{MEK}$ ) in a similar crosslinked polymeric system. This transition is favorable in a good solvent (DMSO in this case), as it allows the nanoparticles to swell such that each microgel particle is close to the others, enhancing the interaction between microgels. ${ }^{35}$ Upon removal of the solvent, the interconnected microspheres become more compact and are strongly aggregated such that it is difficult to redissolve the material. Alternatively, the material can assume the space-filling gel (macrogel) form. Dissolution of this macrogel is impossible, as the microgel-microgel interaction is very strong and can neither be compensated for by the energy of solvation upon addition of solvent nor be compensated for by the application of external energy, for example, heating or sonication.

In the case of the microspheres prepared in $\mathrm{MeCN}$, gelation was not observed even at a monomer feed concentration of 10 wt $\%$ after $24 \mathrm{~h}$ of polymerization (see Figure S1). However, all reaction mixtures turned milky, with no significant change in the solution viscosity. This indicates that stable colloidal particles were formed from high-dilution precipitation polymerization, ${ }^{23}$ which is quite different from the TRPP, in which 
there is phase separation. In the absence of an apparent cmcp, processability tests were conducted using solvents of varying polarities to retroestimate the cmcp (Table 1). N90 microspheres prepared from a 5 wt \% monomer feed concentration were not processable in all test solvents; the particles aggregated such that they would settle at the bottom of the solution (data not shown). However, microspheres that were processable in DMSO, DMF, THF, or MeCN were obtained when the feed concentration was lowered to 4 wt \% (N90-4) in $\geq 6 \mathrm{~h}$. On the other hand, the N90-4 microspheres obtained after $3 \mathrm{~h}$ were processable in all solvents tested but provided a yield of only $40 \%$. Thus, subsequent microsphere syntheses were performed for $24 \mathrm{~h}$ (see Figure S2 for TEM images after polymerization) to optimize the yields $(\geq 90 \%)$. Microspheres prepared at lower crosslinker contents, N70 and N80, using 4 and 5 wt \% monomer feeds, respectively, were also found to be solution-processable. The processability of the microspheres increased with decreasing crosslinker content (i.e., N70 > N80) and decreasing feed concentration (i.e., 4 wt $\%>5$ wt \%).

Synthesis of MIM. Template-Monomer Interactions. The interaction between the template, HTM, and the functional monomer, MAA, is evident in the Fourier transform infrared (FTIR) spectra of HTM, MAA, and a 1:1 mole ratio of the HTM-MAA mixture in MeCN (see Figure S3). Whereas the MAA spectrum showed a strong peak at $1690 \mathrm{~cm}^{-1}$ due to $\mathrm{C}=\mathrm{O}$ stretching, the intensity of this peak markedly reduced upon addition of HTM, accompanied by the appearance of peaks at 1531 and $1400 \mathrm{~cm}^{-1}$, consistent with the asymmetric and symmetrical stretching frequencies of the carboxylate anion, which is indicative of an acid-base interaction between MAA and HTM, that is, deprotonation of MAA with concomitant proton transfer to HTM. ${ }^{37}$ This has also been previously observed between ephedrine and acrylic acid. ${ }^{38}$

MIPs by CTP. HTM-imprinted microspheres were first prepared by CTP with the use of AIBN under the optimum conditions presented in the previous section, that is, $\leq 4 \%$ (w/ w) monomer feed concentration, $80 \%$ crosslinker, and a HTM/ MAA mole ratio of $1: 4$ in $\mathrm{MeCN}$ at $60{ }^{\circ} \mathrm{C}$ for $24 \mathrm{~h}$. Previous reports on HTM-imprinted polymer systems have utilized HTM/MAA ratios of 1:2 (bulk polymer for HTM detection in the $\mathrm{nM}$ to $\mu \mathrm{M}$ range), ${ }^{33} 1: 5$ (bulk polymer selective to HTM against putrescine but not to spermine and spermidine), ${ }^{25}$ and 1:10 (bulk polymer for HTM detection in the $\mathrm{mM}$ range). ${ }^{39}$ However, our results showed that the amount of HTM employed in the preparation of MIMs greatly influenced their cmcp and processabilities. An HTM/MAA ratio of 1:2 resulted in excessive precipitation (and premature $\mathrm{cmcp}$ ) during the early stage of polymerization $(<1 \mathrm{~h})$; this was not observed in the corresponding non-imprinted microspheres. The template molecules, HTM in this case, effectively increase the crosslinking percentage by binding to multiple monomers. Therefore, the addition of template results in a polymer that acts like it has a higher percentage of crosslinker, enhancing particle growth where bigger microspheres are obtained. Ye has also reported on the significant effect of template on the size of the imprinted particle. ${ }^{40,41}$ Early precipitation was circumvented by increasing the HTM/MAA ratio to $1: 10$. This polymer retained a processability comparable to that of NIM; however, both MIM and NIM exhibited similar HTM-binding performances. This is due to the fact that the polymerization carried out under high dilution does not favor the formation of the monomertemplate complex required in the imprinting process. Hence, at a 1:4 mole ratio of $\mathrm{HTM} / \mathrm{MAA}$, at which precipitation was minimal, the imprinting effect was evident, MIMs were obtained in high yields $(>90 \%)$, and the polymers were solution-processable, was chosen for this work.

Previous studies have shown that for MIPs to be highly selective, the formulation should contain at least $70 \mathrm{wt} \%$ crosslinker. $^{20}$ Nevertheless, we found that using a $70 \%$ EGDMA (with 30\% MAA) formulation (M70) also resulted in early precipitation when a 1:4 HTM/MAA formulation was used. Conversely, no precipitation occurred, and the solution turned milky only after $3 \mathrm{~h}$, with the same formulation in the absence of HTM (N70). In addition, no early precipitation was observed on using $80 \%$ (M80) and 90\% crosslinker (M90) reaction mixtures after $1 \mathrm{~h}$ of polymerization. In these systems, the MAA feed was lower (20 and $10 \mathrm{wt} \%$, respectively) than that in M70 (30 wt \% MAA) and the amount of HTM added was also less, in keeping with the 1:4 HTM/MAA ratio. Thus, to minimize changes in the particle size and processability of MIMs, further MIM synthesis by CTP was only conducted using the M80 and M90 formulations.

FTIR (Figure 2A; unextracted MIM) confirmed the presence of HTM within the MIM after polymerization. The peak at $\sim 1550 \mathrm{~cm}^{-1}$ is indicative of the imidazole ring stretching and asymmetric bending of the amino group of $\mathrm{HTM}^{42,43}$ whereas

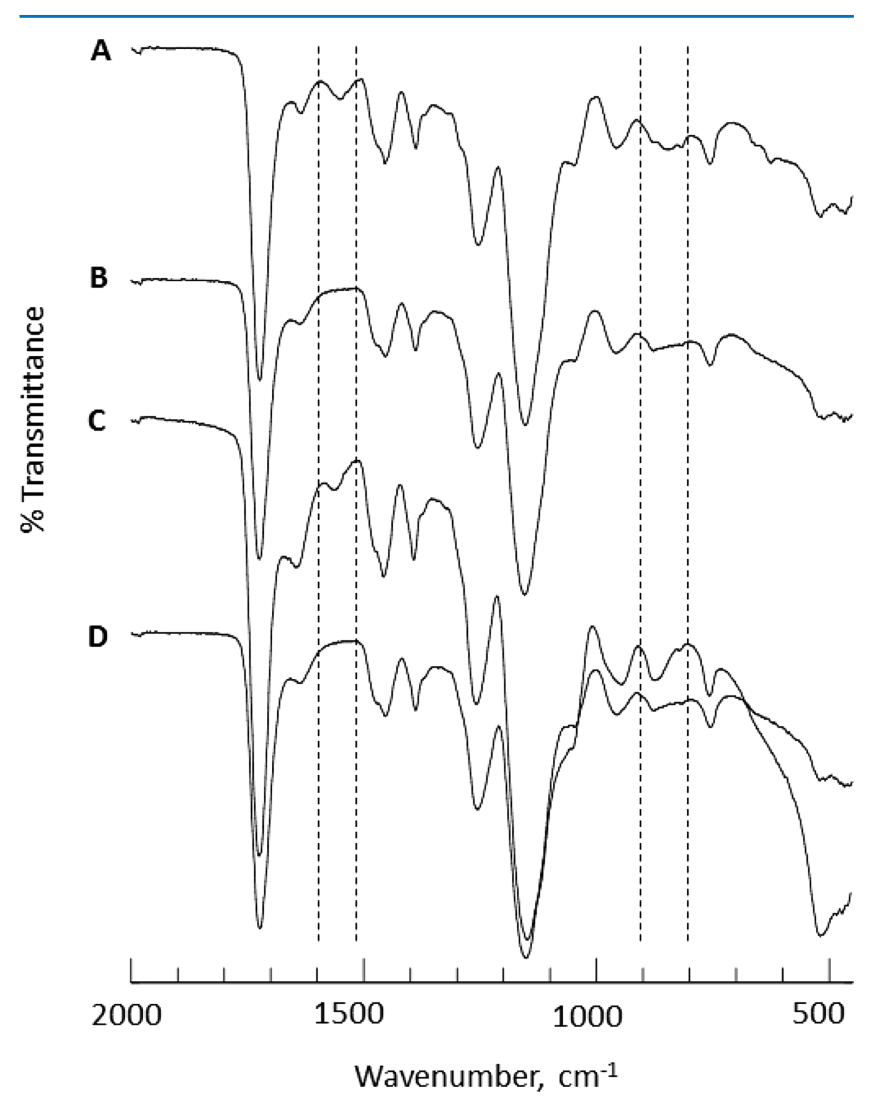

Figure 2. Representative FTIR spectra of HTM-imprinted MIM (A) before template extraction, (B) after template extraction, and (C) after HTM rebinding and of (D) a non-imprinted microsphere. The peak between 900 and $800 \mathrm{~cm}^{-1}$ could be attributed to the HTM imidazole ring in-plane bending. The peak at $\sim 1550 \mathrm{~cm}^{-1}$ is most likely due to a combination of imidazole ring stretching and asymmetric bending of the amino group of HTM and less likely due to the formation of carboxylate (from MAA), as the $\mathrm{C}=\mathrm{O}$ peak did not undergo any significant intensity change, as that expected upon deprotonation of $-\mathrm{COOH}$, before and after HTM binding. 


\section{MIM}

A.

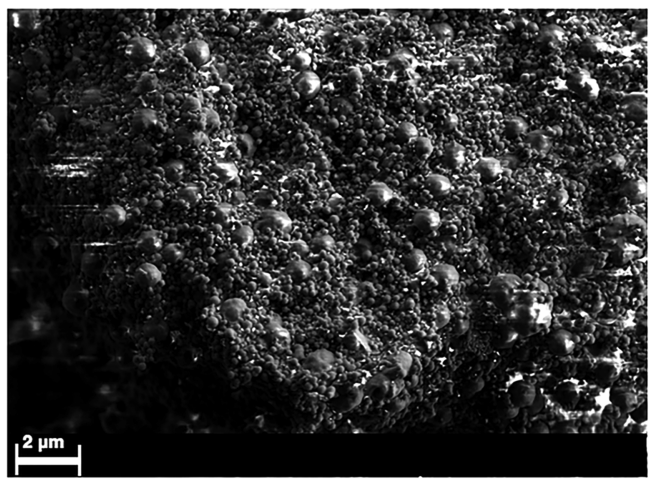

$D_{S E M}=193 \pm 68 \mathrm{~nm} ; 843 \pm 90 \mathrm{~nm}$

$D_{h \text { (DMSO) }}=274 \pm 36 \mathrm{~nm} ; \mathrm{PDI}=0.31$

S.A. $=48 \mathrm{~m}^{2} / \mathrm{g} ;$ Pore volume $=4.1 \mathrm{~cm}^{3} / \mathrm{g}$

B.

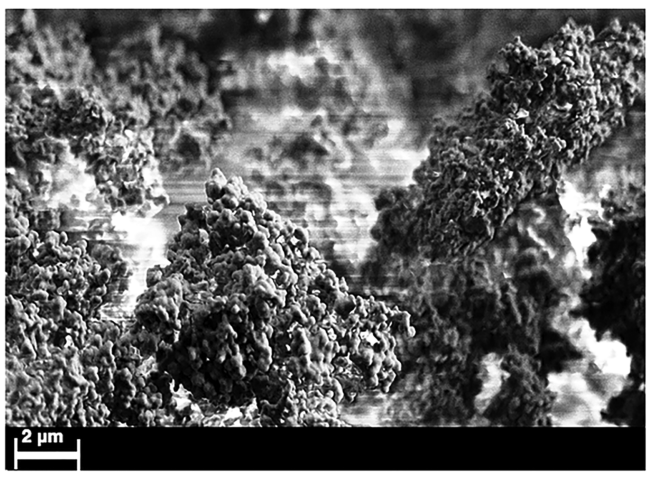

$D_{S E M}=252 \pm 57 \mathrm{~nm}$

$D_{h(\mathrm{DMSO})}=408 \pm 28 \mathrm{~nm} ; \mathrm{PDI}=0.25$

S.A. $=31 \mathrm{~m}^{2} / \mathrm{g} ;$ Pore volume $=9.4 \mathrm{~cm}^{3} / \mathrm{g}$

C.

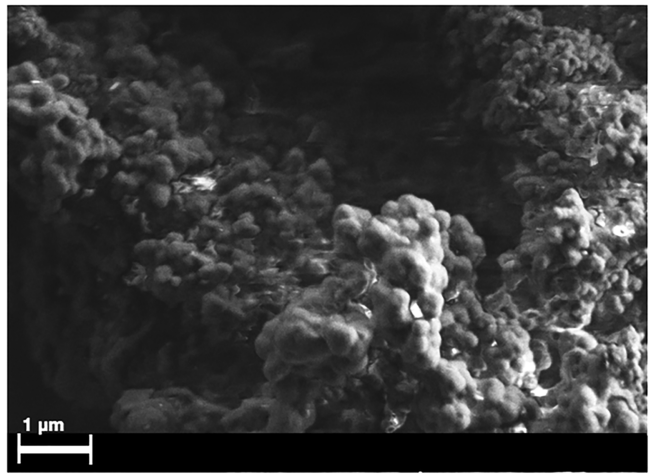

$D_{S E M}=227 \pm 53 \mathrm{~nm}$

$D_{h(\mathrm{DMSO})}=214 \pm 25 \mathrm{~nm} ; \mathrm{PDI}=0.17$

S.A. $=138 \mathrm{~m}^{2} / \mathrm{g} ;$ Pore volume $=40 \mathrm{~cm}^{3} / \mathrm{g}$
NIM

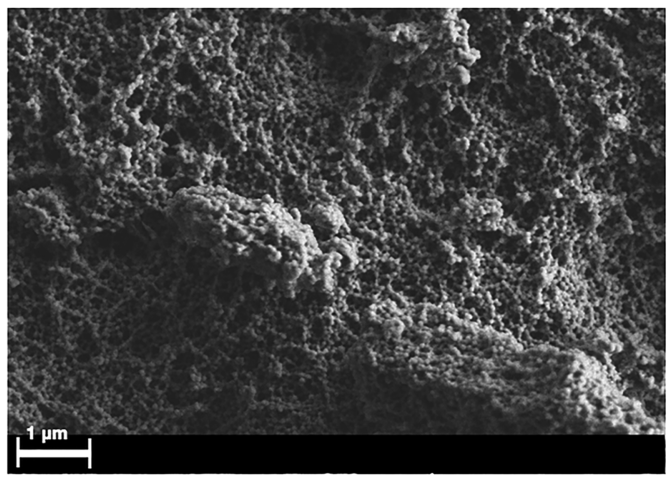

$D_{\text {SEM }}=66 \pm 9 \mathrm{~nm}$

$D_{h(\mathrm{DMSO})}=125 \pm 2 \mathrm{~nm} ; \mathrm{PDI}=0.02$

$S . A=92 \mathrm{~m}^{2} / \mathrm{g} ;$ Pore volume $=17 \mathrm{~cm}^{3} / \mathrm{g}$

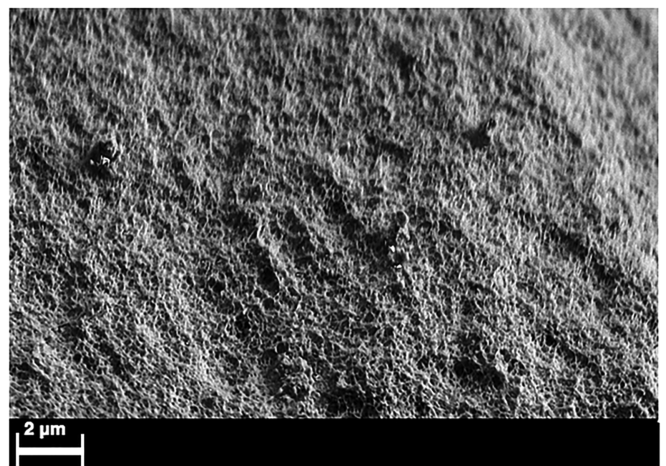

$D_{S E M}=105 \pm 14 \mathrm{~nm}$

$D_{h(\mathrm{DMSO})}=132 \pm 1 \mathrm{~nm} ; \mathrm{PDI}=0.03$

S.A. $=137 \mathrm{~m}^{2} / \mathrm{g} ;$ Pore volume $=27 \mathrm{~cm}^{3} / \mathrm{g}$

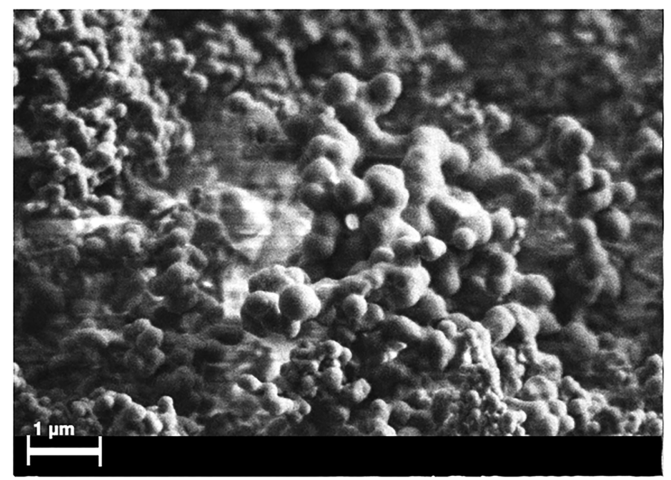

$D_{S E M}=263 \pm 78 \mathrm{~nm}$

$D_{h \text { (DMSO) }} 281 \pm 44 \mathrm{~nm} ; \mathrm{PDI}=0.31$

Figure 3. Scanning electron micrograph (at 33000 magnification, unless indicated), particle size, PDI, surface area (S.A.), and pore volume of (A) CTP-M90 (15 000X) and CTP-N90; (B) CTP-M80 (15 000X) and CTP-N80 (15 000X); and (C) CRP-M80 and CRP-N80. D SEM is the particle size estimated from SEM, $D_{\mathrm{h}}$ is the particle size obtained from DLS, and PDI is from DLS.

the peak around $900-800 \mathrm{~cm}^{-1}$ is attributed to the HTM imidazole ring in-plane bending. These peaks were not visible in the non-imprinted microspheres (Figure 2). In addition, these peaks disappeared after exhaustive extraction of HTM and reappeared upon HTM rebinding, indicating successful creation of HTM-specific recognition cavities within the MIM. Incorporation of the template onto the polymer, that is, creation of imprints, has been demonstrated to occur during the early stage of polymerization, ${ }^{41}$ such that controlling the 
particle growth of the MIM up to its cmcp is not expected to affect the imprinting efficiency.

MIPs by CRP. In addition to that by CTP, MIMs were also prepared by CRP using the RAFT technique. Utilization of CRP in the preparation of highly crosslinked polymers has been reported to provide improved polymer binding performance compared to prepared using the TRPP method. ${ }^{11,12}$ Another advantage of CRP MIMs is the ability of the reactive chains to be reversibly cleaved, allowing further polymerization, which, in our case, is essential for future grafting of MIMs onto polymerizable substrates (e.g., vinyl-silylated substrates) for subsequent sensor fabrication. The mechanism of initiation via RAFT CRP has been thoroughly discussed in the literature. ${ }^{12,18,44}$ In this study, a minimal amount of conventional azo initiator (AIBN) was added to the reaction mixture to form initiating radicals that can react with the RAFT agent. The RAFT agent, MCEBTTC, employed in the synthesis is an efficient and commonly used RAFT initiator for styrenic, ${ }^{32,45}$ acrylic, $^{46}$ and acrylamide ${ }^{47}$ systems, but to the best of our knowledge, this is its first use in MIM/MIP synthesis and with methacrylic monomers.

Preliminary binding studies conducted on the M80 and M90 CTP MIMs showed the M80 formulation to exhibit a better binding behavior than that of M90. Thus, CRP MIMs were only synthesized using the M80 formulation at a $4 \%(\mathrm{w} / \mathrm{w})$ monomer feed concentration in $\mathrm{MeCN}$, at $60{ }^{\circ} \mathrm{C}$ for $24 \mathrm{~h}$, keeping the HTM/MAA mole ratio of 1:4. As with CTP MIMs, premature phase separation of MIMs due to the presence of template was minimal with this formulation, and highly solution processable MIMs were obtained in high yields (>90\%).

Physical Properties of CTP and CRP MIMs. SEM micrographs of microspheres prepared using CTP and CRP are shown in Figure 3, together with their particle sizes, estimated from SEM ( $D_{\text {SEM }}$, collapsed dry state), and PDIs, estimated

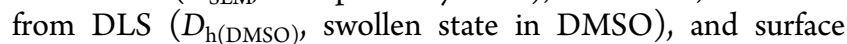
areas obtained from BET. The CTP polymers exist as a network of aggregated particles (Figure 3A,B). The TEM images of the microspheres (CTP-M90 and CTP-N90) obtained after the polymerization step in Figure S2 also showed similar results. Conversely, the SEM images show that the CRP microspheres are clustered (Figure $3 \mathrm{C}$ ). The $D_{\mathrm{h} \text { (DMSO) }}$ and $D_{\mathrm{SEM}}$ of most microspheres are comparable, with the exception of those of CTP-M80, CTP-M90, and CTP-N90. The observed differences in the $D_{\mathrm{h} \text { (DMSO) }}$ (bigger) and $D_{\text {SEM }}$ of these polymers could be attributed to particle aggregation in solution, which, particularly for CTP-M80, was observed to be enhanced in $\mathrm{MeCN}\left(D_{\mathrm{h}(\mathrm{ACN})}=609 \mathrm{~nm}\right)$.

The presence of the template clearly affected the size of the resulting particles, as demonstrated by CTP-M90/N90 (Figure 3A) and CTP-M80/N80 (Figure 3B). In both cases, the MIMs are $\sim 2-3$ times larger than the NIMs (from $D_{\mathrm{h}}$ and $D_{\mathrm{SEM}}$ ), consistent with an earlier observation (during synthesis) of enhanced particle growth, leading to bigger particles for polymerizations conducted in the presence of HTM. In fact, this effect seems to be more pronounced in CTP-M90, for which a small number of bigger particles $(843 \mathrm{~nm})$ are evident from its SEM image. These bigger particles were most likely filtered out from the dispersion and hence not detected in DLS. The formation of a small number of bigger particles in CTPM90, evident from its SEM image, is clearly due to the template increasing the crosslinking percentage by binding to multiple monomers (as discussed earlier) and is exacerbated by the high crosslinker content. This triggers enhanced particle growth, resulting in particles that are bigger than expected. In general, there seems to be no marked difference in particle size between CTP-M90 and -M80 and CTP-N90 and -N80. The PDIs from DLS measurements also show the CTP MIMs to be more polydispersed than the corresponding NIMs, which indicates that the presence of the template may have provided variable rates of particle growth (between monomer clusters interacting with HTM and monomer clusters not interacting with HTM), resulting in a broader particle-size distribution.

Unlike that in CTP microspheres, the presence of the template does not affect the particle growth of CRP microspheres, as both CRP-M80 and CRP-N80 exhibit comparable $D_{\mathrm{h}}$ and $D_{\mathrm{SEM}}$. This is not surprising, as it is well known that chain propagation, and hence polymer growth, is slow and controlled in CRP. It is notable that CRP-M80 is less polydispersed compared to CTP-M90, CTP-M80, and its CRPN80 counterpart. This is different from the result obtained using CTP polymers, where the imprinted polymers are more polydispersed.

As expected, the BET surface areas of the CTP polymers are inversely related to their sizes, such that the surface areas of CTP-M90 $\left(48 \mathrm{~m}^{2} / \mathrm{g}\right)$ and CTP-M80 $\left(31 \mathrm{~m}^{2} / \mathrm{g}\right)$ are much lower ( 2 and 4 times, respectively) than those of their corresponding NIMs (CTP-N90 $=92 \mathrm{~m}^{2} / \mathrm{g}$ and CTP-N80 $=137 \mathrm{~m}^{2} / \mathrm{g}$ ). Both CTP-N90 (pore volume $=17 \mathrm{~cm}^{3} / \mathrm{g}$ ) and CTP-N80 (pore volume $=27 \mathrm{~cm}^{3} / \mathrm{g}$ ) are 4 and 3 times, respectively, more porous than their corresponding MIMs (pore volume $=4$ and 9 $\mathrm{cm}^{3} / \mathrm{g}$, respectively); this may be due to the presence of bigger pores, that is, $>3 \mathrm{~nm}$ (Figure $\mathrm{S} 4$ ). These results suggest that polymerization under NIP conditions gives a higher surface area and pore volume. This is in contrast to that in polymers prepared in the presence of template, in which the presence of HTM significantly altered the polymerization process. Conversely, higher surface areas and larger pore volumes were observed from CRP-M80 compared to those from CRP-N80, where CRP MIM and NIM surface areas $\left(138\right.$ and $123 \mathrm{~m}^{2} / \mathrm{g}$, respectively) and pore volumes (40 and $25 \mathrm{~cm}^{3} / \mathrm{g}$, respectively) were obtained. This observation is indicative that the nature of the polymerization process, particularly the CRP technique, could circumvent the template effect.

Binding Studies. HTM-binding tests were conducted in aqueous solutions using $2 \mathrm{mg}$ of CTP-M80/N80 polymers at varying times from 15 to $240 \mathrm{~min}$. Binding saturation for both MIM and NIM was achieved after $120 \mathrm{~min}$ (Figure S5), where the incubation was performed using a horizontal shaker. The slow binding kinetics could be attributed to the high degree of crosslinking and low swelling degree $(<27 \%$ for both polymers suspended in $1 \mathrm{mM} \mathrm{HTM}$ in $25 \mathrm{mM}$ phosphate buffer at $\mathrm{pH} 7$, data not shown), which hindered the accessibility of the binding sites. ${ }^{48,49}$ Nevertheless, the MIM was found to exhibit a higher binding capacity than that of the NIM, indicating that the imprinting process successfully created HTM-selective binding sites within the MIM.

Optimization of HTM Binding Conditions: Effect of Buffer Concentration and $\mathrm{pH}$. The effect of buffer ionic strength on HTM sorption was determined by varying the concentration of the phosphate $\left(\mathrm{Na}_{2} \mathrm{HPO}_{4}-\mathrm{NaH}_{2} \mathrm{PO}_{4}\right)$ buffer solution from 2 to $100 \mathrm{mM}$ at $\mathrm{pH} \mathrm{7.} \mathrm{At} \mathrm{this} \mathrm{pH}, \mathrm{HTM}$ exists in protonated forms $\mathrm{HTM}^{++}$and $\mathrm{HTM}^{+}$(Figure S6), which can readily interact (by electrostatic interaction) with the deprotonated MAA units $\left(\mathrm{pK}_{\mathrm{a}}=6-7\right)$ randomly distributed along the polymeric network, thereby enhancing HTM sorption. ${ }^{50}$ HTM sorption was observed to decrease with increasing buffer 
A.

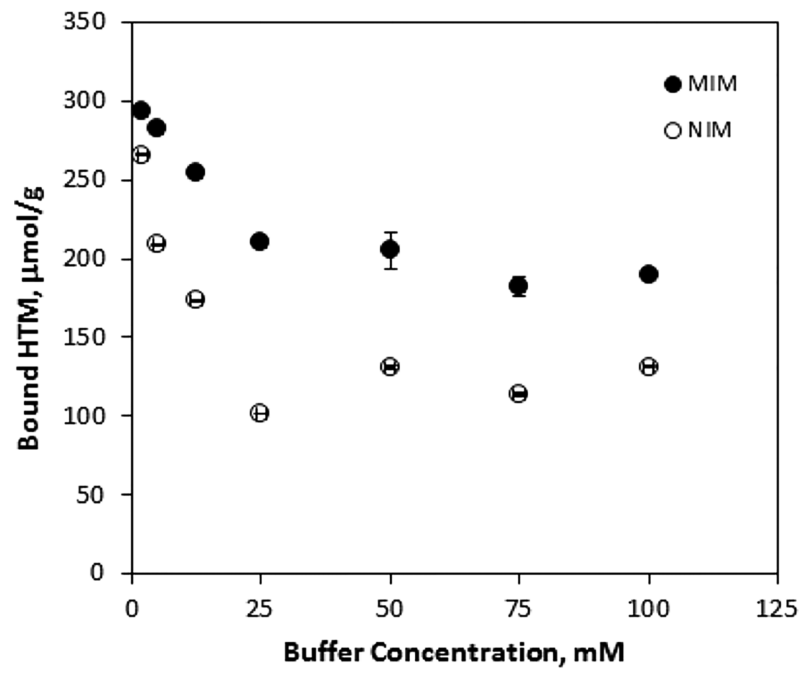

B.

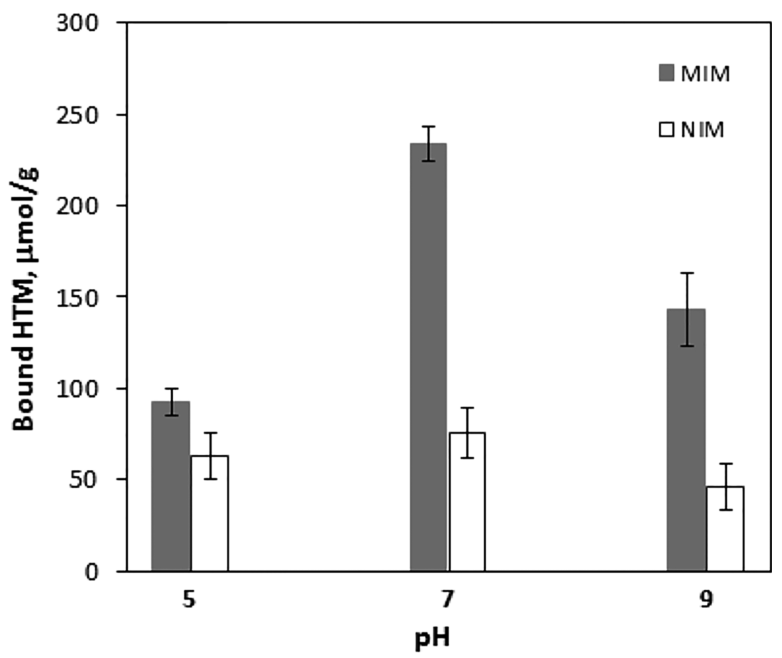

Figure 4. HTM binding on CTP-M80/N80 microspheres at (A) pH 7, with different phosphate buffer concentrations between 2 and $100 \mathrm{mM}$, and (B) at different $\mathrm{pH}$ 's, with a fixed phosphate buffer concentration of $25 \mathrm{mM}$.
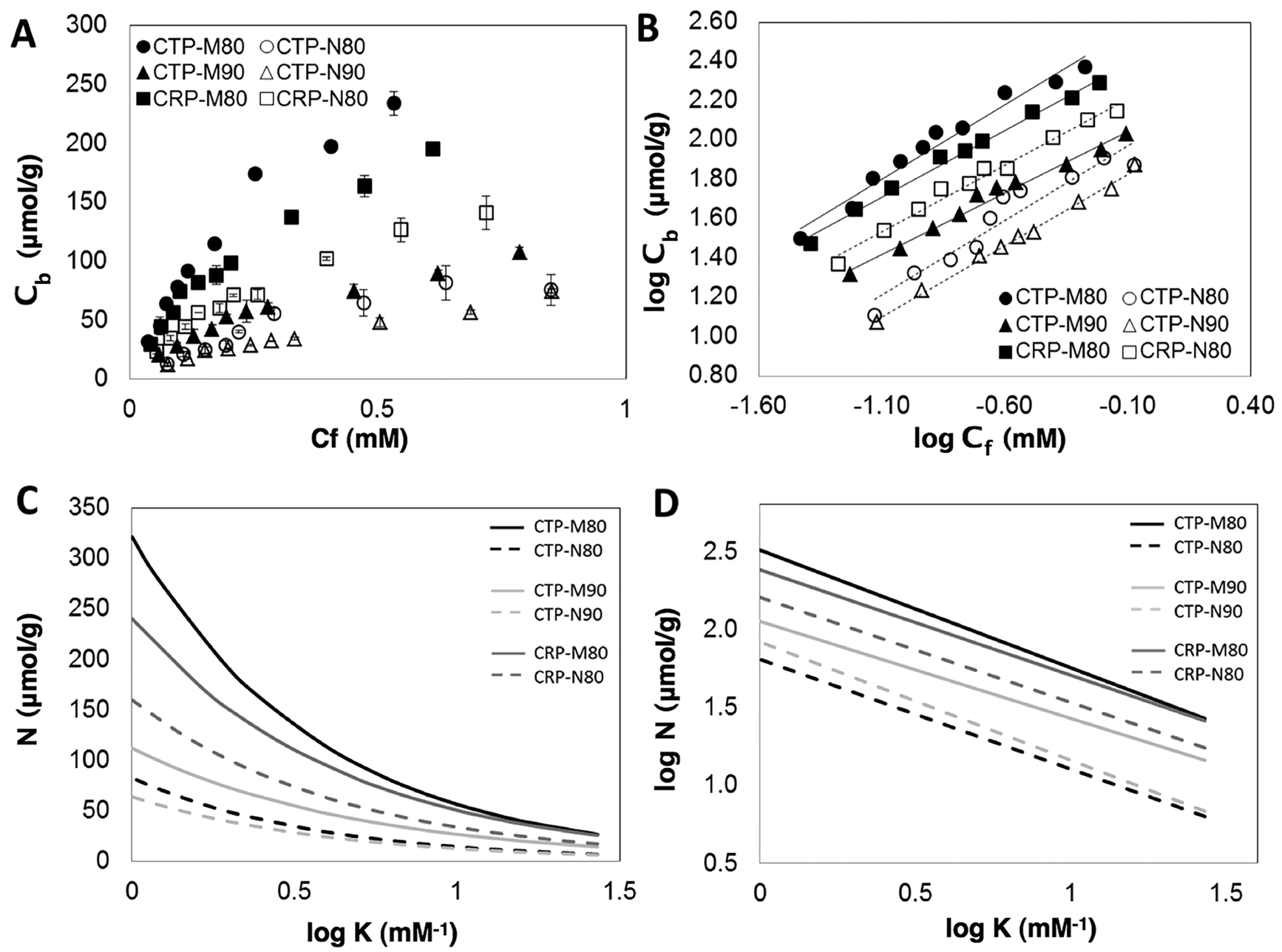

Figure 5. (A) Freundlich binding isotherms, (B) linearized log-log Freundlich binding isotherms, (C) Freundlich affinity distribution expressed in the $N$ vs $\log K$ format, and (D) Freundlich linearized affinity distribution expressed in the $\log N$ vs $\log K$ format, using calculations based on mass. $N$ and $K$ were obtained from the slope $(m)$ and $y$ intercept $a$ of (B) (see Table 2). HTM-binding results were obtained between the 0.10 and $1.0 \mathrm{mM}$ HTM concentration range (aqueous solution, $25 \mathrm{mM}$ buffer, $\mathrm{pH}$ 7) using $2 \mathrm{mg}$ of MIMs and NIMs. Affinity distributions have been generated using the equation $N(K)=2.303 a m\left(1-m^{2}\right) K^{-m}$ over concentration ranges $K_{\min }=1 / F_{\max }$ and $K_{\max }=1 / F_{\min }$. 
Table 2. Binding Parameters for CTP and CRP MIMs and NIMs Estimated from Freundlich Isotherms with Respect to Mass and Specific Surface Area

\begin{tabular}{|c|c|c|c|c|c|c|}
\hline \multirow[b]{2}{*}{ binding parameters } & \multicolumn{2}{|c|}{ СТР-90 } & \multicolumn{2}{|c|}{ CTP-80 } & \multicolumn{2}{|c|}{ CRP-80 } \\
\hline & M90 & N90 & M80 & N80 & M80 & N80 \\
\hline \multicolumn{7}{|c|}{ Calculations Based on Mass } \\
\hline$a^{a}=N_{\mathrm{t}}(\mu \mathrm{mol} / \mathrm{g})+K$ & 128 & 78 & 431 & 112 & 285 & 189 \\
\hline$m^{a}$ & 0.62 & 0.70 & 0.76 & 0.76 & 0.68 & 0.67 \\
\hline$R^{2 a}$ & 0.98 & 0.98 & 0.97 & 0.91 & 0.99 & 0.99 \\
\hline \multicolumn{7}{|c|}{ Calculations Based on Surface Area } \\
\hline$a^{a}=N_{\mathrm{t}}+K$ & 0.42 & 0.067 & 1.12 & 0.012 & 0.32 & 0.19 \\
\hline$m^{a}$ & 0.62 & 0.72 & 0.73 & 0.90 & 0.68 & 0.67 \\
\hline$R^{2 a}$ & 0.98 & 0.99 & 0.98 & 0.98 & 0.99 & 0.99 \\
\hline
\end{tabular}

concentration up to $25 \mathrm{mM}$, at which there is minimal change for both MIM and NIM at $\mathrm{pH} 7$ (Figure 4A). Our findings corroborate those of Trikka et al., ${ }^{25}$ who also observed that increasing the ionic strength (using $\mathrm{NaCl}$ ) decreased the amount of HTM sorbed onto MAA-based bulk MIPs. In the presence of the buffer solution, the electrostatic interactions between the microspheres and HTM could be reduced due to competing interactions with the counterions from the buffer salt. In particular, $\mathrm{Na}^{+}$ions could mask the negative charge density of microspheres. As the buffer concentration increases, more $\mathrm{Na}^{+}$ions are also available to screen the surface charge of the microspheres, thereby diminishing the effect of nonspecific electrostatic interactions between the microspheres and HTM. In fact, the difference in HTM binding between the microspheres and NIM, that is, selective binding attributed to the creation of imprints over the buffer concentration range tested, had not changed significantly, indicating that buffer concentration only affects nonspecific superficial HTM sorption.

Employing the optimized phosphate buffer concentration of $25 \mathrm{mM}$, HTM rebinding tests were also conducted at pH's 5 and 9, at which MAA and HTM exist in different ionic forms (Figure S6). At pH 5, HTM is mostly double-protonated $\left(\mathrm{HTM}^{++}\right)$and MAA is partially protonated. ${ }^{50,51}$ Such conditions do not promote the interaction between HTM and MAA. Thus, as shown in Figure 4B, the MIM exhibited a low affinity toward HTM. At $\mathrm{pH} 9, \mathrm{HTM}^{+}$would have been predominant and MAA, fully deprotonated; HTM binding on the MIM improved as the interaction between the template and functional monomer was more favorable. At $\mathrm{pH} \mathrm{7,} \mathrm{however,}$ optimum MIM binding $(234 \mu \mathrm{mol} / \mathrm{g})$ was observed. At this $\mathrm{pH}, \mathrm{HTM}$ would have been completely protonated (mostly as $\mathrm{HTM}^{++}$and some $\mathrm{HTM}^{+}$), whereas MAA in the microspheres were predominantly deprotonated, creating the most favorable condition for HTM sorption. Whereas MIM binding was significantly affected by $\mathrm{pH}$, NIMs behaved similarly, giving comparable HTM bindings across the $\mathrm{pH}$ range tested. The difference in binding behavior between the MIM and NIM and the loss of binding selectivity within the MIM as a function of $\mathrm{pH}$ indicated that binding in MIM was more selective and primarily governed by favorable interactions between HTM and functional monomer MAA.

Binding Characteristics. Batch binding studies were carried out to evaluate the binding performances of the different MIM and NIM samples at $\mathrm{pH} 7$. The binding data were expressed in two manners: with respect to the mass of the MIP (Figure 5) and with respect to the surface area (Figure S7). All of the MIMs were shown to exhibit higher binding than their corresponding controls (Figures 5A and S7A). Because the binding characteristics of CTP and CRP microspheres toward HTM were studied at concentrations well below saturation binding (0.20-1.0 mM), as such, these binding isotherms have been fitted to, and found to conform with, the Freundlich model, with all log plots (Figures $5 \mathrm{~B}$ and $\mathrm{S7B}$ ) obtaining regression correlation coefficients $\geq 0.91 .^{52}$ These linear log forms yield two fitting parameters, $a$ ( $y$ intercept) and $m$ (slope) (Table 2), which can be used to generate the corresponding affinity distribution over the concentration range studied (i.e., $K_{\min }=1 / F_{\max }$ and $K_{\max }=1 / F_{\min }$ ) that relates the number of binding sites, $N$, for each region of binding sites having an association constant $K$ via the equation $N(K)=2.303 a m\left(1-m^{2}\right) K^{-m}$. The affinity distribution is presented in two formats: $N$ versus $\log K$ (Figures 5C and S7C) and $\log N$ versus $\log K$ (Figures 5D and S7D). The $N$ versus $\log K$ format gives the number of binding sites within the range of association constants, that is, the area under the distribution, whereas the $\operatorname{linear} \log N$ versus $\log K$ format measures the heterogeneity (i.e., the ratio of the number of high-affinity to low-affinity sites) of the binding sites by virtue of slope $m$, such that the flatter the slope, that is, lower the $m$, the higher the concentration of high-affinity sites. ${ }^{53,54}$

From Figure 5C, the binding capacities, $N$ (over the concentration range studied presaturation), for the CTP MIMs are shown to be higher than those for their corresponding NIMs, indicative of the imprinting effect. Whereas CTP-M90 has a lower number of binding sites, its $m$ is flatter $(0.62)$ than that of CTP-M80 $(m=0.76)$, suggesting a higher ratio of high-affinity to low-affinity binding sites. We can deduce that a higher crosslinker content (in CTP-M90) can enhance the formation of higher-affinity binding sites, consistent with the observations of other groups. The amounts of MAA and HTM template added to CTP-M90 were also less than those added to CTP-M80; hence, it is not surprising that the $N$ value for CTP-M80 is greater than that for CTP-M90. In addition, the bigger particles (see Figure 3) from CTP-M90, presumed to result from "template-enhanced particle growth", were separated from the batch used in the binding studies. Conversely, CTP-N90 $(m=0.70)$ has a lower number of binding sites and a higher ratio of high-affinity to low-affinity binding sites than those in CTP-N80 $(m=0.76)$. In the case of CRP microspheres, even though both imprinted CRP-M80 and non-imprinted CRP-N80 exhibited comparable heterogeneities (i.e., $m$ CRP-M80 $=0.68, m$ CRP-N80 = 0.67) (Figure 5D), an imprinting effect was still evident. Typically, prepared MIPs have lower $m$ values (more heterogenous) due to the presence of template in the polymerization step. However, this effect was 
Table 3. Binding Capacity for CTP and CRP MIMs and NIMs at $K=25 \mathrm{mM}^{-1}$ Estimated from the Freundlich Affinity Distribution Given in Figures 5 and S7, Calculated Using eq 3

\begin{tabular}{|c|c|c|c|c|c|c|}
\hline \multirow[b]{2}{*}{ binding capacity } & \multicolumn{2}{|c|}{ СТР-90 } & \multicolumn{2}{|c|}{ CTP-80 } & \multicolumn{2}{|c|}{ CRP-80 } \\
\hline & M90 & N90 & M80 & N80 & M80 & N80 \\
\hline \multicolumn{7}{|l|}{ Calculations Based on Mass } \\
\hline$N(\mu \mathrm{mol} / \mathrm{g})$ & 15.1 & 6.63 & 28.2 & 7.18 & 27.2 & 18.2 \\
\hline$\Delta N^{a}(\mu \mathrm{mol} / \mathrm{g})$ & \multicolumn{2}{|c|}{8.47} & \multicolumn{2}{|c|}{21.0} & \multicolumn{2}{|c|}{9.00} \\
\hline \multicolumn{7}{|c|}{ Calculations Based on Surface Area } \\
\hline$N \times 10^{-2}\left(\mu \mathrm{mol} / \mathrm{m}^{2}\right)$ & 5.01 & 0.52 & 8.11 & 0.03 & 2.99 & 1.80 \\
\hline$\Delta N^{a} \times 10^{-2}\left(\mu \mathrm{mol} / \mathrm{m}^{2}\right)$ & \multicolumn{2}{|c|}{4.49} & \multicolumn{2}{|c|}{8.08} & \multicolumn{2}{|c|}{1.19} \\
\hline
\end{tabular}

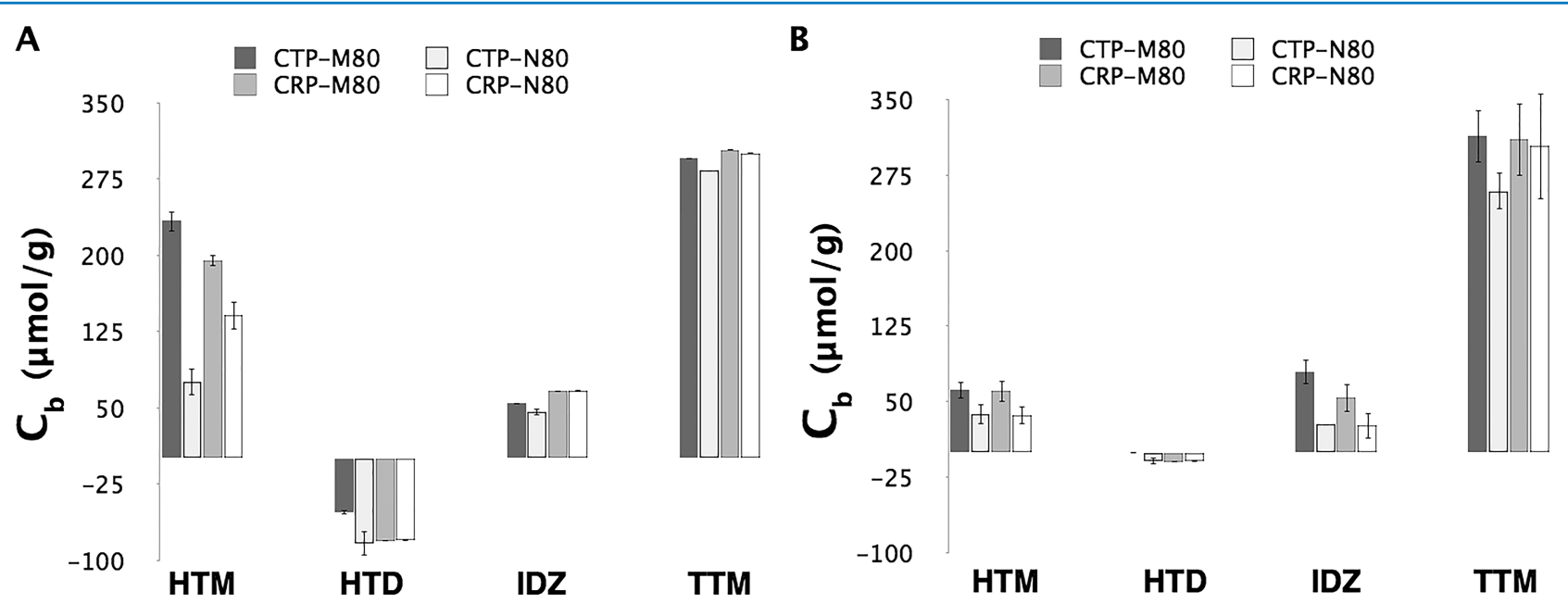

C
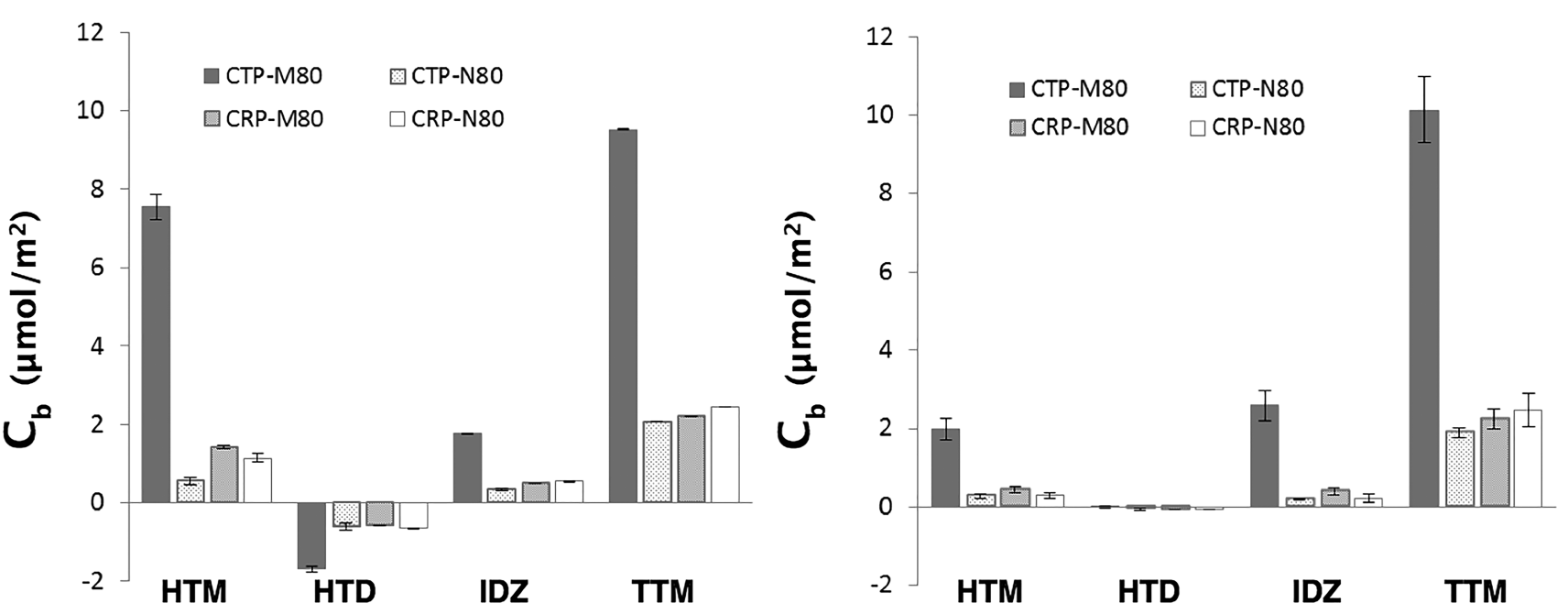

Figure 6. (A) Noncompetitive (cross-binding) and (B) competitive binding assays with HTD, IDZ, and TTM in HTM-imprinted CTP-80 and CRP-80, calculated based on mass. (C) Noncompetitive (cross-binding) and (D) competitive binding assays with HTD, IDZ, and TTM in HTMimprinted CTP-80 and CRP-80, calculated based on surface area. Batch rebinding tests employed $1 \mathrm{mM}$ aqueous analyte solution at $\mathrm{pH}=7 \mathrm{for} 2 \mathrm{~h}$.

not observed in CRP microspheres. A closer look at the affinity distribution plots reveals CRP-80 to possess a higher population of higher-affinity imprinted sites than that in CTP-80 ( $m$ CTP-M80 and $m$ CTP-N80 $=0.76)$. However, CTP-M80 exhibits a higher binding capacity than that of CRPM80, whereas CTP-N80 has a much lower binding capacity than that of CRP-N80.

The data for the calculations based on mass (Figure 5, Table 2) appeared to be comparable to that obtained from the surface area (Figure S7, Table 2). As the MIMs (80 and 90) prepared using CTP have a smaller surface area compared to that of the NIM counterpart, it is not surprising that higher binding capacity values are obtained for MIM than those for NIM. The ratio of the binding capacity between the MIM and the corresponding NIM with respect to the surface area can be exaggerated compared to that from calculations based on mass, that is, the ratio of M80 and N80 by CTP calculated on the basis of the surface area provided 93, whereas the calculation 
based on mass gave 3.8 (Table 2). For CRP, as there is a small difference between the binding capacities and surface areas of the particles, the calculated binding capacities between the MIMs and the corresponding NIMs are also comparable for both calculations.

A quantitative comparison of the binding performances of the microspheres on the basis of $N$, with $K=25 \mathrm{mM}^{-1}$ (i.e., $\log$ $K=1.4$ ), the highest affinity sites across the concentration range studied, is given in Table 3. Among the MIMs, CTPM80, which contains twice the amount of functional monomers and HTM, recorded the highest binding (calculations by mass, $28.2 \mu \mathrm{mol} / \mathrm{g}$; calculations by surface area, $8.11 \times 10^{-2} \mu \mathrm{mol} /$ $\left.\mathrm{m}^{2}\right)$, almost twice that for CTP-M90 $\left(15.1 \mu \mathrm{mol} / \mathrm{g}, 5.01 \times 10^{-2}\right.$ $\left.\mu \mathrm{mol} / \mathrm{m}^{2}\right)$. CRP-M80 provided $27.2 \mu \mathrm{mol} / \mathrm{g}$ and $2.99 \times 10^{-2}$ $\mu \mathrm{mol} / \mathrm{m}^{2}$, whereas CRP-N80 gave $18.2 \mu \mathrm{mol} / \mathrm{g}$ and $1.80 \times$ $10^{-2} \mu \mathrm{mol} / \mathrm{m}^{2}$, with a binding capacity more than 2 times higher compared to that of both CTP-N80 $(7.18 \mu \mathrm{mol} / \mathrm{g} ; 0.03$ $\left.\times 10^{-2} \mu \mathrm{mol} / \mathrm{m}^{2}\right)$ and CTP-N90 $\left(6.63 \mu \mathrm{mol} / \mathrm{g} ; 0.52 \times 10^{-2}\right.$ $\left.\mu \mathrm{mol} / \mathrm{m}^{2}\right)$. Thus, the difference in binding capacities $(\Delta N)$ between MIM and NIM, imparted by the imprinting process, is significantly higher in CTP-80 $\left(21.0 \mu \mathrm{mol} / \mathrm{g} ; 8.08 \times 10^{-2}\right.$ $\left.\mu \mathrm{mol} / \mathrm{m}^{2}\right)$ than that in both CTP-90 $\left(8.47 \mu \mathrm{mol} / \mathrm{g} ; 4.49 \times 10^{-2}\right.$ $\left.\mu \mathrm{mol} / \mathrm{m}^{2}\right)$ and CRP-80 $\left(9.00 \mu \mathrm{mol} / \mathrm{g} ; 1.19 \times 10^{-2} \mu \mathrm{mol} / \mathrm{m}^{2}\right)$. These results suggest that CRP can provide polymers with better structural homogeneity; ${ }^{11}$ however, the selectivity is lower compared to that of CTP-80.

MIP particles synthesized via precipitation polymerization are usually porous. ${ }^{25}$ It is also well documented that these pores carry the recognition sites in each particle. Thus, the templateMIP binding calculations based on per gram polymer considered the template bound to the template-specific cavities, template-nonspecific cavities, as well as the surface of the particles. Conversely, the calculations based on surface area precluded the presence of porous recognition sites in the particles.

On the basis of the results in Figure 3, the alternative calculations generated considering the surface area should not affect the calculated results for CRP-80 as much as those for CTP-80 and -90. CRP polymers were prepared using slow and controlled polymer growth; hence, the size and surface area of the MIMs and NIMs synthesized are comparable. However, for polymers prepared using CTP, the sizes of the CTP MIMs are larger than those of the NIMs, whereas the surface areas of the CTP-NIMs are larger those of the MIMs. If the polymers were prepared in the presence of template molecules, the template could effectively affect the rate of polymer particle growth (vide supra) and alter the surface area of the particle.

Selectivity Studies. The selectivity of the MIMs was investigated via noncompetitive and competitive binding assays, with equimolar amounts of HTD (2), IDZ (3), and TTM (4) (Figure 1) using CTP-80, the best performing MIP, and CRP80. The results after a $2 \mathrm{~h}$ incubation time are shown in Figure 6. It is obvious that CRP- 80 and CTP- 80 are selective toward HTM for both noncompetitive cross-binding and under competitive conditions.

Although HTM and HTD are of similar sizes, both noncompetitive cross-binding and competitive binding tests with CTP-80 yielded negative binding for HTD. With the presence of an additional $\mathrm{COOH}$ group in HTD, the molecule exists as a stable zwitterion at $\mathrm{pH}$ 7. Hence, under this condition, HTD would not favor binding or interaction with the microspheres. This result is similar to that obtained by Ye, where negative template binding was observed for polymers suspended in phosphate buffered at $\mathrm{pH} 6$ and positive binding, for phosphate buffered at $\mathrm{pH} 7 .^{25}$

The smaller IDZ molecule exhibited noncompetitive crossbinding toward CTP-M80. This result is also mirrored in the competitive binding study for both CTP-M80 and CRP-M80, in which the binding capacity of IDZ increased, while maintaining low NIM binding. We surmised that the ability of IDZ to bind more to CTP-M80 in the presence of other analytes is enhanced by its small size ( $0.42 \mathrm{~nm}$ in length), allowing it to fit into the smaller pore cavities, which are not occupied by the bigger analytes. As the $\mathrm{p} K_{\mathrm{a}}$ of $\mathrm{IDZH}^{+}$(i.e., N-3 is protonated) is 6.99 , both neutral and protonated forms of IDZ exist at $\mathrm{pH} 7$, these species are capable of interacting with the MAA $\left(\mathrm{pK}_{\mathrm{a}}=6-7\right)$-based cavities. However, the observed binding capacity of HTM was reduced in the presence of competitors HTD, IDZ, and TTM (Figure 6B).

In both noncompetitive cross-binding and competitive binding tests, TTM exhibited the highest binding to polymers prepared by CTP and CRP surpassing HTM. TTM recorded a CTP-M80 binding of $295 \mu \mathrm{mol} / \mathrm{g}$, slightly higher than that of HTM $(234 \mu \mathrm{mol} / \mathrm{g})$. This binding preference is markedly pronounced in competitive tests, in which TTM $(314 \mu \mathrm{mol} / \mathrm{g}$, CTP-M80; $259 \mu \mathrm{mol} / \mathrm{g}$, CTP-N80) recorded a selective binding (i.e., M80-N80) higher than (5 and 7 times, respectively) that of HTM $(61.5 \mu \mathrm{mol} / \mathrm{g}$, CTP-M80; 37.6 $\mu \mathrm{mol} / \mathrm{g}$, CTP-N80). For CRP MIMs and -NIMs, TTM exhibited the highest binding for both cross-binding and competitive tests at $>300 \mu \mathrm{mol} / \mathrm{g}$ for MIM and NIM. However, selectivity was observed for HTM, where $195 \mu \mathrm{mol} / \mathrm{g}$ for CRPM80 and $141 \mu \mathrm{mol} / \mathrm{g}$ for CRP-N80 were bound. Under competitive conditions, less HTM was bound, at 60.4 and 36.3 $\mu \mathrm{mol} / \mathrm{g}$ for CRP-M80 and CRP-N80, respectively. At $\mathrm{pH} 7$, the amino groups of both HTM and TTM are protonated ( $\mathrm{p} K_{\mathrm{a}}$ 's = 10) and hence interactions (electrostatic) with the functional monomer (MMA) moieties within the binding cavities are expected to be comparable. CTP-M80 also has a higher volume of pores between 0.7 and $3 \mathrm{~nm}$, which can easily fit either a HTM or a TTM molecule. In addition, TTM molecules can interact with each other via $\pi-\pi$ stacking of the phenyl rings, thereby potentially increasing the number of TTM molecules along the binding sites and enhancing their binding capability. Although high TTM binding was observed for CTP and CRP polymers, these interactions are not specific.

Perhaps the most significant difference with the two calculations can be observed between the HTM and TTM bound to the MIM versus NIM for CTP (Figure 6). As the value of the surface areas for CRP-M80 $\left(138 \mathrm{~m}^{2} / \mathrm{g}\right)$, CRP-N80 $\left(123 \mathrm{~m}^{2} / \mathrm{g}\right), 825$ and CTP-N80 $\left(137 \mathrm{~m}^{2} / \mathrm{g}\right)$ are close to each other, their HTM and TTM binding performances are similar. This is in contrast to that in CTP-M80 $\left(31 \mathrm{~m}^{2} / \mathrm{g}\right)$, where the results for the noncompetitive cross-binding and competitive binding for HTM and TTM were higher compared to those for the NIM counterpart.

Despite the competition from TTM, it is worth noting that the potential application targeted for these HTM-selective MIMs is for sensing the presence of HTM in fish, as an indicator of fish spoilage, or in tissue or urine. Among the three analytes tested, only HTD, which did not exhibit affinity toward the HTM MIMs, is a potential competitor in the real situation of testing for fish spoilage. 


\section{CONCLUSIONS}

The solution-processable HTM-imprinted microspheres used in this study were prepared via high-dilution CTP and CRP using the RAFT technique. The microspheres obtained below the apparent $\mathrm{cmcp}$ in $\mathrm{MeCN}$ were found to be processable in a number of organic test solvents of varying polarities, whereas those prepared in DMSO were not, even at a high dilution. Processable HTM CTP MIMs were prepared in high yields (>90\%), with the optimal 4\% (w/w) monomer feed concentration in $\mathrm{MeCN}$ containing a 1:4 HTM/MAA ratio and 80 or $90 \mathrm{wt} \%$ (M80 or M90, respectively) EGDMA at 60 ${ }^{\circ} \mathrm{C}$ for $24 \mathrm{~h}$. CRP MIMs were synthesized using only $80 \mathrm{wt} \%$ (CRP-M80) EGDMA.

The presence of the template, HTM, has been observed to promote binding to multiple monomers and to increase the effective crosslinking percentage. This effect of the template on the physical properties of the resulting microspheres was evident in the CTP systems and not in the CRP systems. The CTP MIMs were bigger, with lower surface areas, and more polydispersed than the corresponding NIMs, which indicated the presence of template-introduced particle growth. However, CTP-NIMs were more porous than CTP MIMs. Conversely, the presence of the template did not seem to affect the particle growth of CRP microspheres, as both the MIM and NIM exhibited comparable sizes, expected in RAFT polymerization. However, contrary to the results obtained using CTP, the CRP MIMs exhibited a higher porosity and had a larger surface area than CRP-NIMs.

The data obtained form the binding studies fitted to the Freundlich model, where the binding isotherms and affinity distribution (over the concentration range studied) showed the binding capacity, $N$, for the CTP MIMs to be higher than that of their corresponding NIMs, indicative of the imprinting effect. Whereas $N$ for CTP-M80 is twice that for CTP-M90, CTPM90 exhibited a flatter slope, $m$, demonstrating a higher ratio of high-affinity to low-affinity binding sites. This suggested that a higher crosslinker content enhances the formation of HTMbinding sites. In the case of the CRP microspheres, both imprinted CRP-M80 and non-imprinted CRP-N80 exhibited comparable heterogeneities, suggesting that the binding sites are as good as those obtained from CTP-90. Among the MIMs, CTP-M80, which contained twice the amounts of MAA and HTM compared to those in CTP-M90, recorded the highest $N$ $(28.2 \mu \mathrm{mol} / \mathrm{g})$, almost twice those for CTP-M90 $(15.1 \mu \mathrm{mol} /$ g) at $K=25 \mathrm{mM}^{-1}$, the highest affinity point across the concentration range studied. Conversely, CRP-M80 provided an $N$ value of $27.2 \mu \mathrm{mol} / \mathrm{g}$, comparable to that of CTP-M80, whereas the value for CRP-N80 $(18.2 \mu \mathrm{mol} / \mathrm{g})$ was 2 times higher than that for CTP-N80 $(7.18 \mu \mathrm{mol} / \mathrm{g})$ and CTP-N90 $(6.63 \mu \mathrm{mol} / \mathrm{g})$. As a result, the selective binding capacity $\left(N_{\mathrm{MIM}}\right.$ $\left.-N_{\text {NIM }}\right)$ imparted by the imprinting process was significantly higher in CTP-80 than that in both CTP-90 and CRP-80. From these results, the binding capacity calculations for CTP based on surface area can be exaggerated, especially if there is a small surface area, compared to the calculations based on mass. For CRP, as there is a small difference between the calculated binding capacities and the surface areas of the two particles, the difference obtained between the MIMs and the corresponding NIMs is also small.

Noncompetitive and competitive binding assays against HTM analogues HTD, IDZ, and TTM showed CTP MIMs and CRP MIMs to be selective to HTM under cross-binding and competitive conditions, although a reduction in HTM binding was observed in the latter test. TTM was also found to preferentially bind to both CTP-M80 and CRP-M80 over HTM in both noncompetitive cross-binding and competitive binding tests. We attributed this to the ability of TTM to easily compete with HTM for access to binding sites by virtue of their similarity in size, functionality, charge, and interaction through their phenyl rings, thereby enhancing TTM's access to binding sites.

This study has demonstrated successful creation of imprints in solution-processable MIMs, allowing an alternative synthetic pathway toward the fabrication of MIP-based materials. Although previous studies have shown that polymers obtained under controlled free-radical precipitation conditions gave a better binding performance compared to that of CTP, in this study, CRP-M80 prepared with MCEBTTC gave a lower binding capacity but a higher ratio of high-affinity to lowaffinity sites compared to those of CTP-M80. These processable MIMs can be appropriately functionalized (demonstrated to be possible by CRP-RAFT) to facilitate further reactions in solution, such as attachment to supports and immobilization on a substrate to produce membranes/thin films for HTM recognition.

\section{ASSOCIATED CONTENT}

\section{Supporting Information}

The Supporting Information is available free of charge on the ACS Publications website at DOI: 10.1021/acsomega.6b00144.

Photographs of CTP-80 and CRP-80 microspheres after polymerization; sample TEM micrograph (CTP-90), FTIR spectra of HTM, MAA, and the HTM-MAA mixture, pore size distributions of MIMs and NIMs, HTM sorption of CTP-M80 and -N80 at different binding times, structural forms of HTM and microspheres at different $\mathrm{pH}$ 's, and Freundlich binding isotherm plots based on surface area (PDF)

\section{AUTHOR INFORMATION}

\section{Corresponding Authors}

*E-mail: rso@ateneo.edu. Fax: +632 4261323 (R.C.S.).

*E-mail: Clovia.Holdsworth@newcastle.edu.au. Tel: +612 9215481. Fax: +612 49215472 (C.I.H.).

\section{Notes}

The authors declare no competing financial interest.

\section{ACKNOWLEDGMENTS}

The authors acknowledge the scholarship awarded by the Commission on Higher Education (CHED) of the Philippines to EFR under its Ph.D. Sandwich Program.

\section{REFERENCES}

(1) Mosbach, K.; Ramström, O. The emerging technique of molecular imprinting and its future impact of biotechnology. Nat. Biotechnol. 1996, 14, 163-170.

(2) McCluskey, A.; Holdsworth, C. I.; Bowyer, M. C. Molecularly imprinted polymers (MIPs): sensing, an explosive new opportunity? Org. Biomol. Chem. 2007, 5, 3233-3244.

(3) Sellergren, B.; Lepistoe, M.; Mosbach, K. Highly enantioselective and substrate-selective polymers obtained by molecular imprinting utilizing noncovalent interactions. NMR and chromatographic studies on the nature of recognition. J. Am. Chem. Soc. 1988, 110, 5853-5860.

(4) Ye, L.; Mosbach, K. Molecularly imprinted microspheres as antibody binding mimics. React. Funct. Polym. 2001, 48, 149-157. 
(5) Renkecz, T.; László, K.; Horváth, V. Molecularly imprinted microspheres prepared by precipitation polymerization at high monomer concentrations. Mol. Imprinting 2014, 2, 1-17.

(6) Braunecker, W.; Matyjaszewski, K. Controlled/living radical polymerization: Features, developments, and perspectives. Prog. Polym. Sci. 2007, 32, 93-146.

(7) Zu, B.; Pan, G.; Guo, X.; Zhang, Y.; Zhang, H. Preparation of molecularly imprinted polymer microspheres via atom transfer radical precipitation polymerization. J Polym. Sci., Part A: Polym. Chem. 2009, 47, 3257-3270.

(8) Chiefari, J.; Chong, Y. K.; Ercole, F.; Krstina, J.; Jeffrey, J.; Le, T. P. T.; Mayadunne, R.; Meijs, G. F.; Moad, C.; Moad, G.; Rizzardo, E.; Thang, S. H. Living Free-Radical Polymerization by Reversible Addition-Fragmentation Chain Transfer: The RAFT Process. Macromolecules 1998, 31, 5559-5562.

(9) Solomon, D. H. Genesis of the CSIRO polymer group and the discovery and significance of nitroxide-mediated living radical polymerization. J Polym. Sci., Part A: Polym. Chem. 2005, 43, 57485764.

(10) Otsu, T.; Yoshida, M. Role of Initiator-Transfer AgentTerminator (Iniferter) in Radical Polymerizations: Polymer Design by Organic Disulfides as Iniferters. Macromol. Rapid Commun. 1982, 3, 127-132.

(11) Vaughan, A. D.; Sizemore, S. P.; Byrne, M. E. Enhancing molecularly imprinted polymer binding properties via controlled/ living radical polymerization and reaction analysis. Polymer 2007, 48, 74-81.

(12) Pan, G. Q.; Zu, B. Y.; Guo, X. Z.; Zhang, Y.; Li, C. X.; Zhang, H. Q. Preparation of molecularly imprinted polymer microspheres via reversible addition-fragmentation chain transfer precipitation polymerization. Polymer 2009, 50, 2819-2825.

(13) Zhou, T.; Jørgensen, L.; Mattebjerg, M. A.; Chronakis, I. S.; Ye, L. Molecularly imprinted polymer beads for nicotine recognition prepared by RAFT precipitation polymerization: a step forward towards multi-functionalities. RSC Adv. 2014, 4, 30292-30299.

(14) Lu, C.-H.; Zhou, W.-H.; Han, B.; Yang, H.-H.; Chen, X.; Wang, X.-R. Surface-Imprinted Core-Shell Nanoparticles for Sorbent Assays. Anal. Chem. 2007, 79, 5457-5461.

(15) Titirici, M. M.; Sellergren, B. Thin Molecularly Imprinted Polymer Films-Reversible Addition-Fragmentation Chain Transfer Polymerization. Chem. Mater. 2006, 18, 1773-1779.

(16) Zhang, H. Q. Controlled/“living" radical precipitation polymerization: A versatile polymerization technique for advanced functional polymers. Eur. Polym. J. 2013, 49, 579-600.

(17) Vaughan, A. D.; Zhang, J. B.; Byrne, M. E. Enhancing therapeutic loading and delaying transport via molecular imprinting and living/controlled polymerization. AIChE J. 2010, 56, 268-279.

(18) Xu, S.; Li, J.; Chen, L. Molecularly imprinted polymers by reversible addition-fragmentation chain transfer precipitation polymerization for preconcentration of atrazine in food matrices. Talanta 2011, 85, 282-289.

(19) Boonpangrak, S.; Whitcombe, M. J.; Prachayasittikul, V.; Mosbach, K.; Ye, L. Preparation of molecularly imprinted polymers using nitroxide-mediated living radical polymerization. Biosens. Bioelectron. 2006, 22, 349-354.

(20) Biffis, A.; Graham, N. B.; Siedlaczek, G.; Stalberg, S.; Wulff, G. The Synthesis, Characterization and Molecular Recognition Properties of Imprinted Microgels. Macromol. Chem. Phys. 2001, 202, 163-171.

(21) Chen, Z.; Hua, Z.; Wang, J.; Guan, Y.; Zhao, M.; Li, Y. Molecularly imprinted soluble nanogels as a peroxidase-like catalyst in the oxidation reaction of homovanillic acid under aqueous conditions. Appl. Catal., A 2007, 328, 252-258.

(22) Pasetto, P.; Maddock, S. C.; Resmini, M. Synthesis and characterisation of molecularly imprinted catalytic microgels for carbonate hydrolysis. Anal. Chim. Acta 2005, 542, 66-75.

(23) Cutivet, A.; Schembri, C.; Kovensky, J.; Haupt, K. Molecularly Imprinted Microgels as Enzyme Inhibitors. J. Am. Chem. Soc. 2009, 131, 14699-14702.
(24) Vaihinger, D.; Landfester, K.; Kräuter, I.; Brunner, H.; Tovar, G. E. Molecularly imprinted polymer nanospheres as synthetic affinity receptors obtained by miniemulsion polymerization. Macromol. Chem. Phys. 2002, 203, 1965-1973.

(25) Trikka, F. A.; Yoshimatsu, K.; Ye, L.; Kyriakidis, D. A. Molecularly imprinted polymers for histamine recognition in aqueous environment. Amino Acids 2012, 43, 2113-2124.

(26) Becker, K.; Southwick, K.; Reardon, J.; Berg, R.; MacCormack, J. N. Histamine Poisoning Associated With Eating Tuna Burgers. JAMA, J Am. Med. Assoc. 2001, 285, 1327-30.

(27) Taylor, S. L.; Stratton, J. E.; Nordlee, J. A. Histamine Poisoning (Scombroid Fish Poisoning): An Allergy-Like Intoxication. J. Toxicol., Clin. Toxicol. 1989, 27, 225-40.

(28) Bachert, C. The role of histamine in allergic disease: re-appraisal of its inflammatory potential. Allergy 2002, 57, 287-296.

(29) Beaven, M. A.; Robinson-White, A.; Roderick, N. B.; Kauffman, G. L. The demonstration of histamine release in clinical conditions: A review of past and present assay procedures. Klin. Wochenschr. 1982, $60,873-881$.

(30) Marquardt, D. L. Histamine. Clin. Rev. Allergy 1983, 1, 343-351.

(31) U.S. Department of Health and Human Services. CPG Sec. 540.525 Decomposition and Histamine Raw, Frozen Tuna and MahiMahi; Canned Tuna; and Related Species. http://www.fda.gov/ ICECI/ComplianceManuals/CompliancePolicyGuidanceManual/ ucm074506.htm (accessed July 11, 2016).

(32) Pascual, S.; Urbani, C. N.; Monteiro, M. J. Functionalization of Polymer Nanoparticles Formed by Microemulsion RAFT-Mediated Polymerization. Macromol. React. Eng. 2010, 4, 257-263.

(33) Horemans, F.; Alenus, J.; Bongaers, E.; Weustenraed, A.; Thoelen, R.; Duchateau, J.; Lutsen, L.; Vanderzande, D.; Wagner, P.; Cleij, T. J. MIP-based sensor platforms for the detection of histamine in the nano- and micromolar range in aqueous media. Sens. Actuators, $B$ 2010, 148, 392-398.

(34) Slomkowski, S.; Alemán, J. V.; Gilbert, R. G.; Hess, M.; Horie, K.; Jones, R. G.; Kubisa, P.; Meisel, I.; Mormann, W.; Penczek, S.; Stepto, R. F. T. Terminology of polymers and polymerization processes in dispersed systems (IUPAC Recommendations 2011). Pure Appl. Chem. 2011, 83, 2229-2259.

(35) Frank, R. S.; Downey, J. S.; Yu, K.; Stöver, H. D. H. Poly(divinylbenzene-alt-maleic anhydride) Microgels: Intermediates to Microspheres and Macrogels in Cross-Linking Copolymerization. Macromolecules 2002, 35, 2728-2735.

(36) Downey, J. S.; McIsaac, G.; Frank, R. S.; Stöver, H. D. H. Poly(divinylbenzene) Microspheres as an Intermediate Morphology between Microgel, Macrogel, and Coagulum in Cross-Linking Precipitation Polymerization. Macromolecules 2001, 34, 4534-4541.

(37) Cabaniss, S. E.; McVey, I. F. Aqueous infrared carboxylate absorbances: aliphatic monocarboxylates. Spectrochim. Acta, Part A 1995, 51, 2385-2395.

(38) Brisbane, C.; McCluskey, A.; Bowyer, M.; Holdsworth, C. I. Molecularly imprinted films of acrylonitrile/methyl methacrylate/ acrylic acid terpolymers: influence of methyl methacrylate in the binding performance of L-ephedrine imprinted films. Org. Biomol. Chem. 2013, 11, 2872-2884.

(39) Tong, A.; Dong, H.; Li, L. Molecular imprinting-based fluorescent chemosensor for histamine using zinc(II) - protoporphyrin as a functional monomer. Anal. Chim. Acta 2002, 466, 31-37.

(40) Yoshimatsu, K.; Yamazaki, T.; Chronakis, I. S.; Ye, L. Influence of template/functional monomer/cross-linking monomer ratio on particle size and binding properties of molecularly imprinted nanoparticles. J. Appl. Polym. Sci. 2012, 124, 1249-1255.

(41) Long, Y.; Philip, J. Y. N.; Schillén, K.; Liu, F.; Ye, L. Insight into molecular imprinting in precipitation polymerization systems using solution NMR and dynamic light scattering. J. Mol. Recognit. 2011, 24, 619-30.

(42) Ramírez, F. J.; Tunón, I.; Collado, J. A.; Silla, E. Structural and Vibrational Study of the Tautomerism of Histamine Free-Base in Solution. J. Am. Chem. Soc. 2003, 125, 2328-2340. 
(43) Collado, J. A.; Ramírez, F. J. Vibrational spectra and assignments of histamine dication in the solid state and in solution. J. Raman Spectrosc. 2000, 31, 925-931.

(44) Moad, G.; Rizzardo, E.; Thang, S. H. Living Radical Polymerization by the RAFT Process. Aust. J. Chem. 2005, 58, 379410.

(45) Zayas, H. A.; Truong, N. P.; Valade, D.; Jia, Z.; Monteiro, M. J. Narrow Molecular Weight and Particle Size Distributions of Polystyrene 4-arm Stars Synthesized by RAFT Mediated Miniemulsions. Polym. Chem. 2013, 4, 592-599.

(46) Truong, N. P.; Jia, Z.; Burges, M.; McMillan, N. A. J.; Monteiro, M. J. Self-Catalyzed Degradation of Linear Cationic Poly(2dimethylaminoethyl acrylate) in Water. Biomacromolecules 2011, 12, $1876-1882$

(47) Tran, N. T. D.; Jia, Z.; Truong, N. P.; Cooper, M. A.; Monteiro, M. J. Fine Tuning the Disassembly Time of Thermoresponsive Polymer Nanoparticles. Biomacromolecules 2013, 14, 3463-3471.

(48) Aguilar, M. R.; Elvira, C.; Gallardo, A.; Vázquez, B.; Román, J. S. Smart Polymers and their Applications as Biomaterials. In Topics in Tissue Engineering; Ashammakhi, N., Reis, R., Chiellini, E., Eds.; Biomaterials and Tissue Engineering Group: 2007; Vol. 3, pp 1-27. http://www.oulu.fi/spareparts/ebook_topics_in_t_e_vol3/.

(49) Booker, K. M.; Holdsworth, C. I.; Bowyer, M. C.; McCluskey, A. Ionic Liquids as Porogens in the Synthesis of Molecularly Imprinted Polymers. In Applications of Ionic Liquids in Science and Technology; Handy, S., Ed.; InTech, 2011; pp 197-212. http://www.intechopen. com/books/applications-of-ionic-liquids-in-science-and-technology/ ionic-liquids-as-porogens-in-the-synthesis-of-molecularly-imprintedpolymers.

(50) Bongaers, E.; Alenus, J.; Horemans, F.; Weustenraed, A.; Lutsen, L.; Vanderzande, D.; Cleii, T. J.; Troost, F. J.; Brummer, R. J.; Wagner, P. A MIP-based biomimetic sensor for the impedimetric detection of histamine in different $\mathrm{pH}$ environments. Phys. Status Solidi A 2010, 207, 837-843.

(51) Peeters, M.; Troost, F. J.; Mingels, R. H.; Welsch, T.; van Grinsven, B.; Vranken, T.; Ingebrandt, S.; Thoelen, R.; Cleij, T. J.; Wagner, P. Impedimetric detection of histamine in bowel fluids using synthetic receptors with $\mathrm{pH}$-optimized binding characteristics. Anal. Chem. 2013, 85, 1475-1483.

(52) Umpleby, R. J.; Baxter, S. C.; Rampey, A. M.; Rushton, G. T.; Chen, Y.; Shimizu, K. D. Characterization of the heterogeneous binding site affinity distributions in molecularly imprinted polymers. $J$. Chromatogr. B: Anal. Technol. Biomed. Life Sci. 2004, 804, 141-149.

(53) Umpleby, R. J.; Baxter, S. C.; Bode, M.; Berch, J. K. J.; Shah, R. N.; Shimizu, K. D. Application of the Freundlich adsorption isotherm in the characterization of molecularly imprinted polymers. Anal. Chim. Acta 2001, 435, 35-42.

(54) Rushton, G. T.; Karns, C. L.; Shimizu, K. D. A critical examination of the use of the Freundlich isotherm in characterizing molecularly imprinted polymers (MIPs). Anal. Chim. Acta 2005, 528, 107-113. 